\title{
Keeping track of time
}

Daily time management, participation, and time-related interventions for children, adolescents, and young adults with neurodevelopmental disorders

Birgitta Wennberg

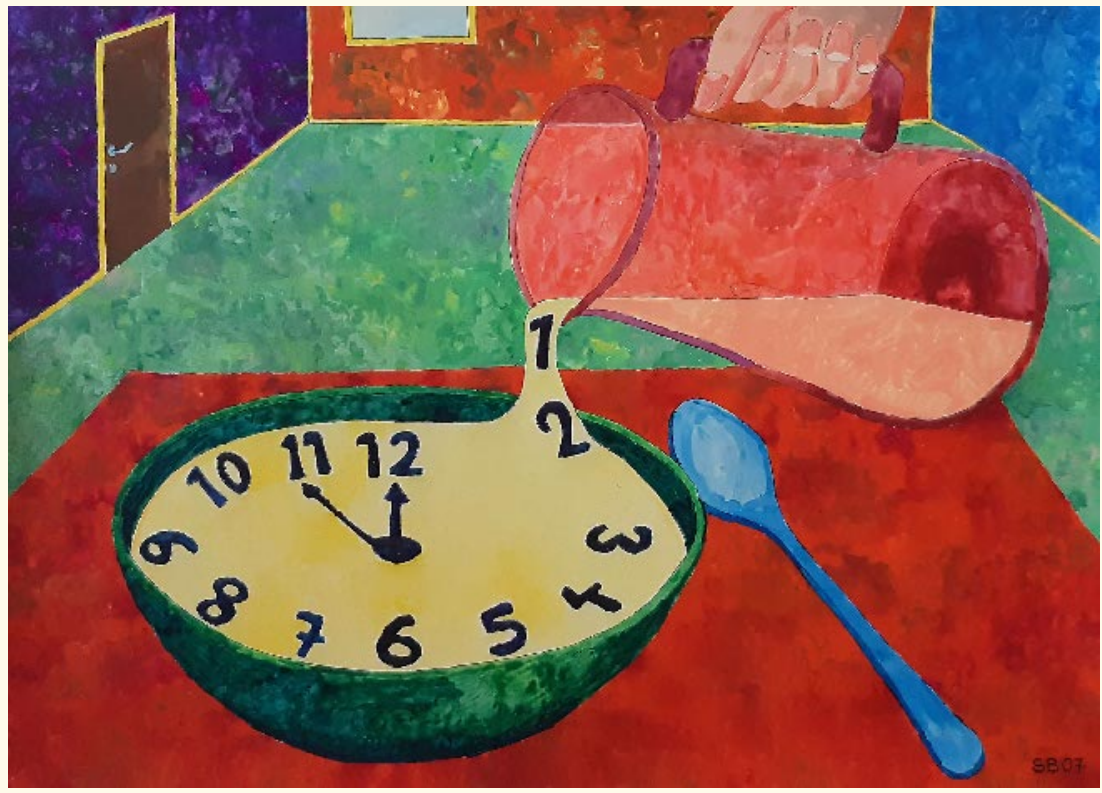




\title{
Keeping track of time
}

Daily time management, participation and time-related interventions in children, adolescents and young adults with neurodevelopmental disorders

\author{
Birgitta Wennberg
}

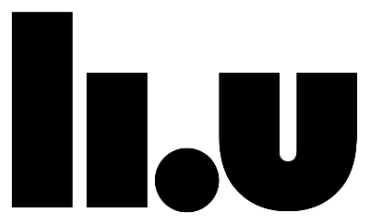

LINKÖPING UNIVERSITY

Child and Adolescent Psychiatry

Center for Social and Affective Neuroscience (CSAN)

Department of Clinical and Experimental Medicine (IKE)

Linköping University, Sweden

Linköping 2019 
Keeping track of time. Daily time management, participation and time-related interventions in children adolescents and young adults with neurodevelopmental disorders.

(c) Birgitta Wennberg, 2019

Cover Illustration: Frukostbild, by Sven Björsten.

Photos: Kersti Sköld

Published articles have been reprinted with the permission of the copyright holder.

Printed in Sweden by LiU-Tryck, Linköping, Sweden, 2019

ISBN 978-91-7929-955-2

ISSN 0345-0082 


\section{CONTENTS}

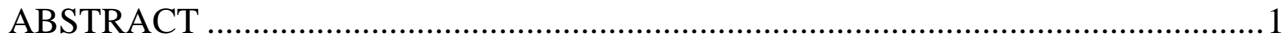

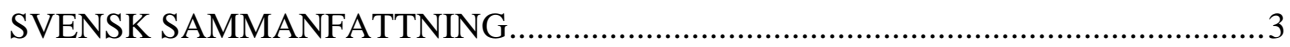

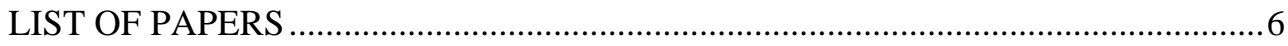

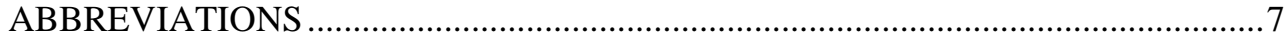

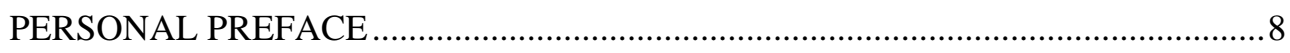

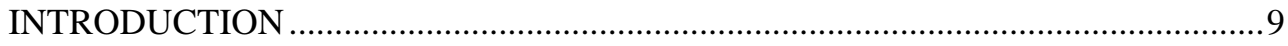

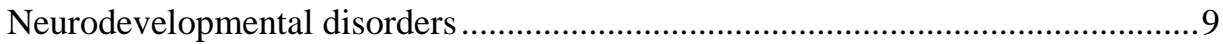

Attention-deficit/hyperactivity disorder ................................................. 9

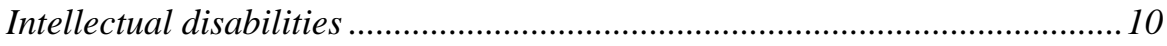

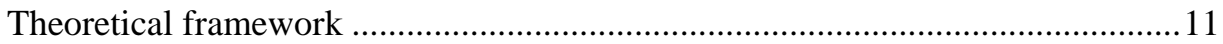

International Classification of Functioning, Disability and Health ...............11

Canadian Model of Occupational Performance and Engagement ................. 12

Daily time management and time processing ability ....................................... 13

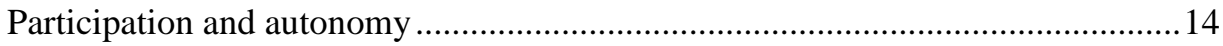

People with ID and time-related difficulties in everyday life .............................15

Children with ADHD and time-related difficulties in everyday life.....................16

Self-rated autonomy in children and young adults with ID and ADHD ...............17

Time-related interventions......................................................................... 18

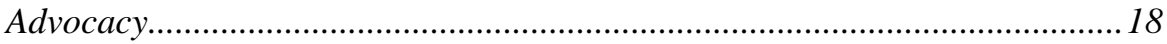

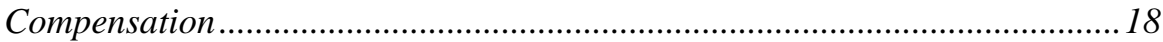

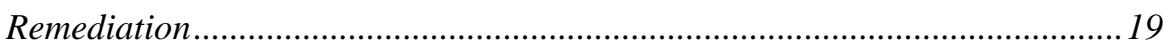

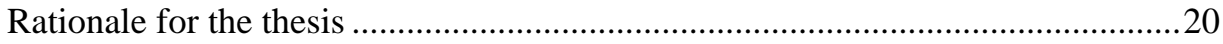

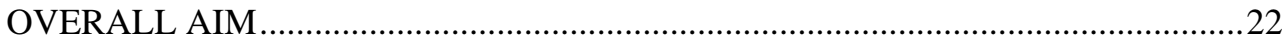

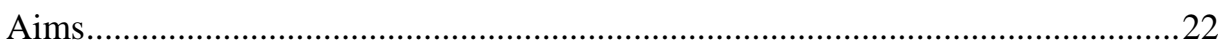

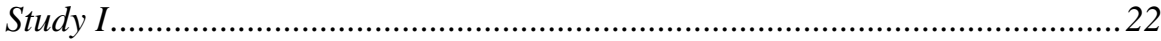

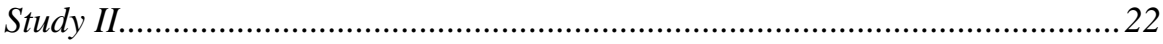

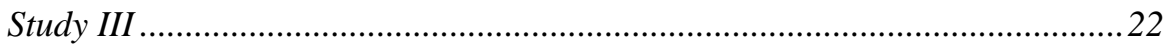

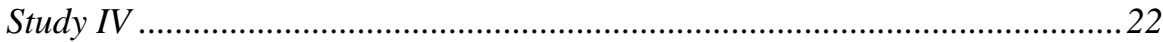


METHOD .23

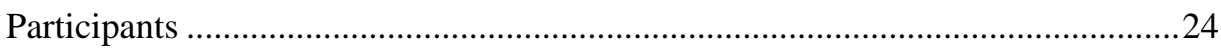

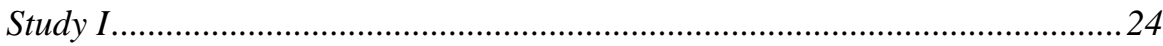

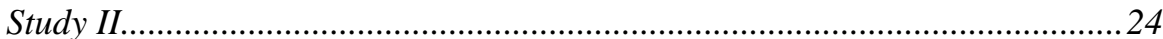

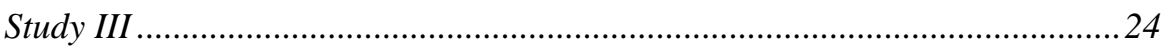

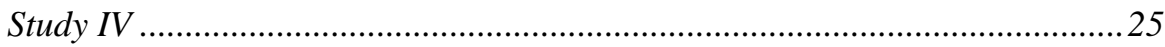

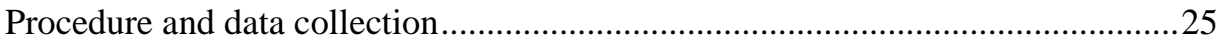

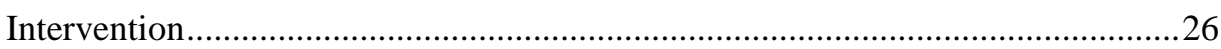

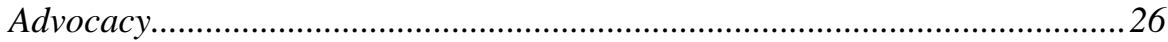

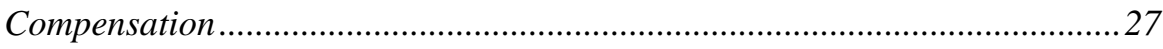

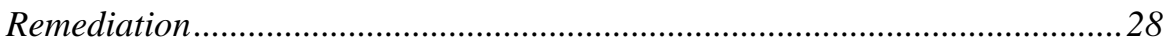

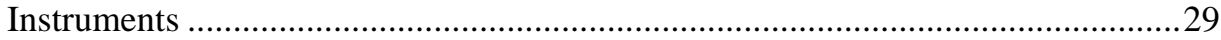

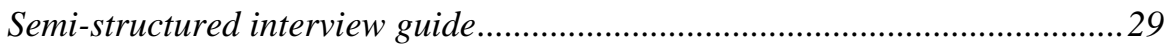

The Kit for assessing Time processing ability (KaTid) .................................29

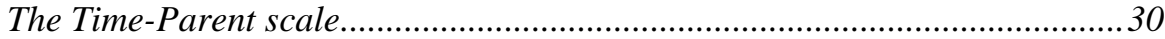

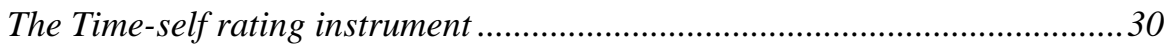

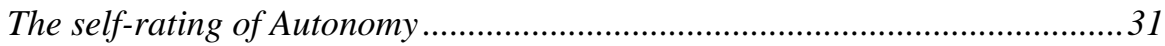

The Canadian Occupational Performance Measure (COPM) .......................31

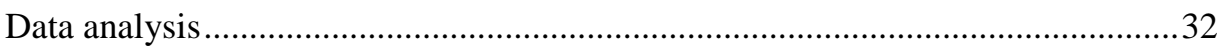

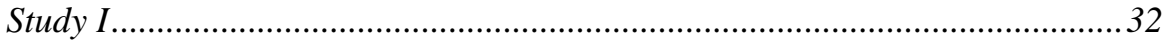

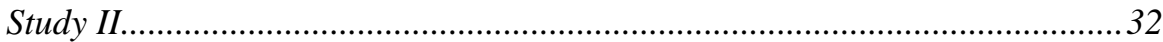

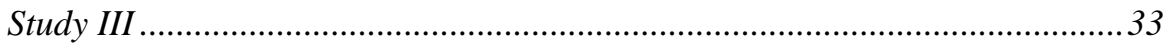

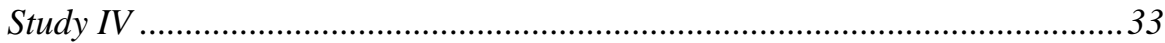

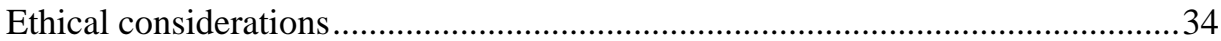

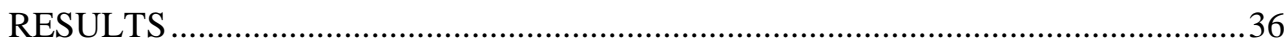

Study I. Participation when using CAD - from the perspective of people

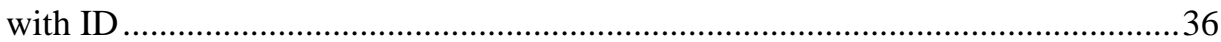

Study II. Effectiveness of time-related interventions in children with ADHD aged 9-15 years: a randomized controlled study ............................................. 37

Study III. DTM and autonomy in school-age children with ADHD, ID, and TD children show different patterns.

Study IV. Occupational performance and outcome of time-related interventions for children with ADHD - children and parents ratings 
Summary of findings

Increased participation in daily activities using CADs

Participation and autonomy in performing activities can be dependent on TPA

Specific difficulties in TPA, DTM and in autonomy for children with ADHD and children with ID compared to TD children.

Time-related interventions increase TPA and DTM in children and adolescents with ADHD 45

Participation used as both a means and a goal in the research process

Methodological considerations

Aspects of generalizability of the findings. .49

Choice of design and data collection methods. .50

Aspects of data analysis and trustworthiness. 51

Clinical implications .52

Future research .54

CONCLUSIONS .55

ACKNOWLEDGEMENTS .57

REFERENCES .59 



\section{ABSTRACT}

The overall aim of this thesis was to investigate daily time management (DTM) and time-related interventions aiming to enhance participation in everyday activities among school-age children and young adults with neurodevelopmental disorders.

In study I, experiences of participation when using time assistive devices (TADs) in daily activities were investigated from the perspective of young adults (aged 17-37) with intellectual disabilities (ID) $(n=9)$, using semi structured interviews. In studies II and IV, a new multimodal time-related intervention consisting of psychoeducation, compensation with TADs and timeskills training, was investigated in children aged 9-15 with attentiondeficit/hyperactivity disorder (ADHD). Study II was a randomized controlled trial (RCT) with an intervention group $(n=19)$ and a control group $(n=19)$. The aim of study III was to describe DTM, time processing ability (TPA) and selfrated autonomy in children aged 9-15 with ADHD $(n=47)$, compared to children with ID $(n=47)$ and typically developing (TD) children $(n=47)$. In study IV, occupational performance and satisfaction were evaluated $(n=27)$. In studies II, III and IV, a source for data collection included assessment, proxy report and self-reports.

Using TADs (study I) increased participation in activities in all areas of daily life: self-care, activities at work or school and leisure time activities. A feeling of having more control led to health benefits. Participants described participation restrictions related to attitudes from their social network towards participation and attitudes towards the use of TADs from the individuals themselves. Study II showed that the children in the intervention group increased their TPA significantly more compared to the control group, mostly in terms of time orientation. The parents in the intervention group rated their children's DTM as significantly more improved compared to the parents of the children in the control group. However, according to the children themselves, there was no statistically significant improvement in their DTM. The psychoeducation for parents and school staff was appreciated, but did not increase children's TPA and DTM on its own. The majority of parents and children (study IV) rated the children's occupational performance and satisfaction significantly higher at follow-up than at baseline. In general, children rated their occupational performance and satisfaction higher than their parents did, both at baseline and at follow-up. Most goals decided on by the children and their parents involved daily routines and time orientation. Study III showed that children with ADHD and children with ID had significantly lower TPA, DTM and autonomy compared to TD children. Children with ADHD showed higher levels of self-rated autonomy compared to children with ID, but the reverse was found in DTM. However, there was significant diversity among children with ADHD and children with ID, which was not explained by age. Some children had difficulties at every level of 
TPA, while others were skilled at every level. The level of self-rated autonomy followed the level of TPA.

In conclusion, this thesis revealed that children with ADHD and ID have the same overall pattern of TPA but may have a delayed TPA, which affects their DTM and autonomy, and thereby also influences their participation in daily activities. The results show that a multimodal time-related intervention using TADs and time-skills training could increase TPA and DTM in children with ADHD aged 9-15 years with time deficits. Experiences from young adults with ID also show increased participation in daily activities and health benefits using TADs. It is recommended that TPA and DTM should be measured to identify difficulties in TPA and DTM in children with ADHD and to offer tailored timerelated interventions in addition to medication.

Keywords: ADHD, autonomy, ID, daily time management, intervention, occupational therapy, participation, time assistive devices, time processing ability. 


\section{SVENSK SAMMANFATTNING}

Barn, ungdomar och vuxna personer med neuropsykiatriska funktionsnedsättningar som attention-deficit/hyperactivity (ADHD) och intellektuell funktionsnedsättning kan ha svårigheter att förstå och hantera tid. Problemen är inte alltid synliga men kan ändå leda till nedsatt autonomi och delaktighet $\mathrm{i}$ vardagslivets aktiviteter hemma, vid utbildning och arbete och på fritiden. För att kompensera för de svårigheter som kan uppstå kan de som har behov av det få tillgång till tidshjälpmedel. Exempel på tidshjälpmedel är visuell timer, individuellt utformat schema som visar när och vad man planerat att göra under en dag eller en vecka, digitalt schema med tidsstöd och appar med tidsoch påminnelsestöd. Personer med intellektuell funktionsnedsättning har, som grupp, haft tillgång till tidshjälpmedel under en längre tid men det finns få vetenskapliga studier som beskriver användarens erfarenheter av att använda dem. För barn och ungdomar med ADHD är tidshjälpmedel ett relativt nytt område och inga kontrollerade vetenskapliga studier har undersökt om tidshjälpmedel och andra tidsrelaterade insatser, som att träna tidsuppfattning, kan vara effektivt.

Det övergripande syftet med avhandlingen var att undersöka tidshantering i vardagen och tidsrelaterade interventioner som syftar till att underlätta delaktighet $i$ vardagslivet för barn, ungdomar och unga vuxna med neuropsykiatriska funktionsnedsättningar.

I studie I intervjuades 9 personer $(17-37$ år $)$ med intellektuell funktionsnedsättning om sin användning av tidshjälpmedel och hur dessa påverkade deras känsla av delaktighet i vardagsaktiviteter. Deltagarna var nio kvinnor och två män och de hade haft sitt tidshjälpmedel mellan 1,5 månad till 2 år. Deltagarna kände sig mer delaktiga i vardagens alla aktiviteter, både hemma, i skolan/på arbetet och på fritiden. De beskrev minskad oro och minskade fysiska besvär och även en känsla av att ha en mer vuxen roll jämfört med tidigare. Det fanns dock inskränkningar i delaktigheten, dels beroende på den sociala omgivningens inställning till delaktighet och till deras egen inställning till att använda hjälpmedel.

I studie II och IV deltog barn med ADHD, 9 - 15 år som medicinerade mot ADHD. I studie II, som var en randomiserad kontrollerad studie med interventionsgrupp ( $n=19)$ och kontrollgrupp $(n=19)$ var syftet att undersöka hur en ny intervention påverkade barnens tidsuppfattning och tidshantering. Barnens tidsuppfattning mättes med ett standardiserat bedömningsinstrument (KaTid), tidshanteringen skattades både av föräldrarna med ett frågeformulär (Tid-F) och av barnen med ett självskattningsformulär (Tid-S). Interventionen bestod av tre delar: i/ psyko-edukation (utbildning) till föräldrar och coacher, ii/ 
arbetsterapeutiska insatser som inkluderade förskrivning av tidshjälpmedel och anpassningar i miljön samt att iii/ barnen fick träna sin tidsuppfattning med hjälp av ett program med tio utmaningar med stegrande svårighetsgrad. Barnen fick hjälp av en coach i träningen. För att jämföra om enbart psykoedukation räckte som intervention fick barnen i kontrollgruppen bara tillgång till den insatsen medan barnen i interventionsgruppen även fick de två andra insatserna. Barnen i interventionsgruppen ökade både sin tidsuppfattning och sin tidshantering signifikant mer jämfört med barnen i kontrollgruppen. I studie $I V$ deltog 27 barn från studie II. Data samlades in med ett personcentrerat bedömningsinstrument (CMOP) där barn och föräldrar identifierade aktivitetsproblem, valde problemområden med mål för interventionerna samt var för sig skattade aktivitetsutförande och nöjdhet för varje problemområde. Syftet i studie IV var att undersöka hur den ovan beskrivna interventionen (från studie II) påverkade de mål som barnen och deras föräldrar hade bestämt för intervention och att jämföra barnens skattningar av sitt utförande och hur nöjda de var med det, med föräldrarnas skattningar. Ett kompletterande syfte var att identifiera vilka mål som barnen och föräldrarna valde gemensamt. Resultatet i studie IV visade att såväl barn som föräldrar skattade barnens utförande och nöjdhet med utförandet som signifikant högre efter intervention. Barnen skattade generellt både utförande och nöjdhet högre än sina föräldrar. De flesta mål handlade om vardagsrutiner som att klara morgon - och kvällsrutiner inom den överenskomna tiden, att ha koll på tiden under en aktivitet men också att veta och hålla reda på vad som ska hända och när under den närmaste dagen, veckan och månaden.

I studie III var syftet att jämföra tidsuppfattning, tidshantering och självskattad autonomi mellan barn och ungdomar i åldern 9-15 år med ADHD, med intellektuell funktionsnedsättning och med barn och ungdomar utan funktionsnedsättning. Data samlades in med KaTid, föräldraskattning Tid-F och med ett frågeformulär där barnen skattade sin autonomi. Barnen med ADHD hade lägre tidsuppfattning, tidshantering och autonomi jämfört med barn utan funktionsnedsättning. Barnen med intellektuell funktionsnedsättning hade lägre tidsuppfattning och autonomi än barnen med ADHD men deras tidshantering skattades som högre av deras föräldrar jämfört med föräldrarna till barnen med ADHD. Det visade sig också att det generella mönstret för tidsuppfattning inte skiljde sig åt mellan barnen med ADHD, barnen med intellektuell funktionsnedsättning och barnen utan funktionsnedsättning men att barnen med ADHD och de med intellektuell funktionsnedsättning generellt visade sig vara senare i sin utveckling av tidsuppfattningen. Det var dock skillnader i tidsuppfattning mellan barnen inom samma grupp (diagnos) som inte kunde förklaras med ålder. Ett annat fynd var också att barnens självskattade autonomi var kopplat till barnens tidsuppfattning. Barnen med hög nivå av tidsuppfattning skattade också sin grad av autonomi som hög.

Sammantaget har avhandlingen visat att barn och ungdomar med ADHD och barn och ungdomar med intellektuell funktionsnedsättning har samma 
övergripande mönster av tidsuppfattning som barn utan funktionsnedsättning men att de kan ha en försenad utveckling av tidsuppfattning. Detta kan påverka deras tidshantering och autonomi och därmed också deras delaktighet i dagliga aktiviteter. Resultaten visar att en tidsrelaterad intervention bestående av kompensation med tidshjälpmedel och träning av tidsuppfattning kan öka tidsuppfattning och tidshantering i vardagsaktiviteter hos barn med ADHD i åldern 9-15 år som har svårigheter med tid. Erfarenheter från unga vuxna med intellektuell funktionsnedsättning visar också en ökad delaktighet i dagliga aktiviteter och hälsofördelar med tidshjälpmedel. Utifrån resultaten i studierna rekommenderas att tidsuppfattning och tidshantering ska bedömas för att identifiera svårigheter i tidsuppfattning och tidshantering hos barn med ADHD. Detta för att erbjuda skräddarsydda tidsrelaterade interventioner som ett komplement till medicinering. 


\section{LIST OF PAPERS}

I. Wennberg, B. \& Kjellberg, A. (2010). Participation when using cognitive assistive devices - from the perspective of people with intellectual disabilities. Occupational Therapy International, 17(4), 168-176, doi:10.1002/oti.296

II. Wennberg, B., Janeslätt, G., Kjellberg, A., \& Gustafsson, P. A. (2018). Effectiveness of time-related interventions in children with ADHD aged 9-15 years: a randomized controlled study. European Child \& Adolescent Psychiatry, 27(3), 329-342. doi:10.1007/s00787-017-1052-5

III. Wennberg, B., Kjellberg, A., Gustafsson, P. A., Almqvist L., \& Janeslätt, G. Daily time management and autonomy in school-age children with ADHD, intellectual disabilities, and typically developing children show different patterns (submitted).

IV. Wennberg, B., Janeslätt, G., Gustafsson, P. A., \& Kjellberg, A. Occupational performance goals and outcomes of time-related interventions for children with ADHD (submitted). 


\section{ABBREVIATIONS}

ATC Assistive technology for cognition

ADHD Attention-deficit/hyperactivity disorder

CAD Cognitive assistive device

COPM Canadian Occupational Performance Measure

CMOP-E Canadian Model of Occupational Performance and Engagement

DTM Daily time management

DSM-5 Diagnostic and Statistical Manual of Disorder No. 5

ES Effect size

HOPS Homework, Organization, and Planning System

ICF International Classification of Functioning, Disability and Health

ICF-CY International Classification of Functioning, Disability and Health: Children and Youth Version

ID Intellectual disabilities

OST Organizational skills training

OT Occupational therapist

OTMP Organizational time management planning

PATHKO Parents and Teachers Helping Kids Organize

PROM Patient-reported outcome measure

RCT Randomized controlled trial

TD Typically developing (children)

TAD Time assistive device

TPA Time processing ability 


\section{PERSONAL PREFACE}

I have worked as an occupational therapist for 40 years. Throughout my professional life, I have worked with people with various cognitive difficulties, first with adults with intellectual disabilities (ID), and then for many years with children, adolescents and adults with attention-deficit/hyperactivity disorder (ADHD), autism spectrum disorder, ID and acquired brain injuries.

Questions about participation have always been of the utmost importance to me. What opportunities do the people I meet have to understand, to make informed decisions and to have control? Based on this, before becoming a doctoral student, I have had the privilege of running various projects designed to facilitate participation in everyday activities, at home, in the workplace and during leisure time.

Over the years, I have seen many positive changes in both knowledge of and attitudes to cognitive impairment, and also in the form of practical tools for increased participation with cognitive assistive devices. Devices that compensate for difficulties in understanding and managing time - time assistive devices have been used for a number of years. As a clinical occupational therapist, I have prescribed time assistive devices. In my work at a specialist centre for communicative and cognitive support, I have worked as a consultant for a large number of prescriptions of time assistive devices, mainly for people with autism spectrum disorder and/or ID. I have seen how time assistive devices and support from the social network has led to increased participation for many people with neurodevelopmental disorders. In my work, I have also become aware that children and adolescents with ADHD often have difficulties managing time in their everyday lives. However, access to time assistive devices and other interventions to overcome difficulties in everyday life related to time have been limited for children and adolescents with ADHD. There also are few studies in which people with neurodevelopmental disorders themselves describe their use of time assistive devices, how it affects everyday activities and the possibility of increased participation. For children and adolescents with ADHD, time-related interventions are a new area that needed to be explored.

I was delighted to have the opportunity to start research in this area!

This thesis can contribute to knowledge about daily time management for people with neurodevelopmental disorders. I also hope that the thesis can arouse interest and inspiration in providing tools for those children, adolescents and adults with neurodevelopmental disorders who need time-related interventions. 


\section{INTRODUCTION}

The focus of this thesis is people with neurodevelopmental disorders and their participation in daily activities. The ability to manage time is essential in order to participate actively in everyday life, to have opportunities to influence, to be in control and to make decisions. To enhance participation in everyday life for children and young adults with neurodevelopmental disorders, it is of interest to investigate the groups' cognitive difficulties related to time. It is also important to develop knowledge about which interventions are effective and to listen to users' experiences of time assistive devices.

\section{Neurodevelopmental disorders}

Neurodevelopmental disorder is an umbrella term listed in the Diagnostic and Statistical Manual of Disorder No. 5 (DSM-5) and used for disabilities in the neurological system and the brain that occur during the developmental period (American Psychiatric Association, 2013). Examples of diagnoses include attention-deficit/hyperactivity disorder (ADHD), autism spectrum disorder (ASD), intellectual disabilities (ID) and specific learning disorder. Problems related to these disorders are not always visible, but can still lead to reduced autonomy and participation in everyday life (Swedish Agency for Health Technology Assessment and Assessment of Social Services, 2013). Problems in everyday life often relate to cognitive impairment and the individual's interaction with the environment. This implies difficulties in everyday activities at home, in education, at work and in leisure activities.

The focus of this thesis is on children and adolescents with ADHD, and children, adolescents and young adults with ID.

\section{Attention-deficit/hyperactivity disorder}

According to DSM-5 (American Psychiatric Association, 2013), the core symptoms of ADHD are difficulties with attention or hyperactivity or a combination of the two (Faraone et al., 2015). The symptoms appear to change during the child's development, with preschool children more often having problems with hyperactivity/impulsivity than attention. Difficulties with hyperactivity/impulsivity tend to decrease over time, while difficulties with attention appear to remain relatively stable (Wahlstedt, 2009). Those children who have the combined type of ADHD are expected to experience the greatest difficulties with attention at older ages, as hyperactivity/impulsivity are expected to decrease. 
The prevalence data for ADHD varies between different countries and studies depending on factors such as definition, population studied and screening instruments used (Polanczyk, Salum, Sugaya, Caye, \& Rohde, 2015; Swedish Agency for Health Technology Assessment and Assessment of Social Services, 2013). However, it is widely agreed that about 6-7\% of school-aged children have ADHD and there is a tendency for boys to be overweight (Thomas, Sanders, Doust, Beller, \& Glasziou, 2015; Willcutt, 2012). There appear to be gender differences, as girls have been found to have greater intellectual impairment, less hyperactivity and fewer problems with externalization and internalization (Gaub \& Carlson, 1997). Difficulties tend to appear early, often before the age of seven, and remain in adulthood in about $25-65 \%$ of cases (Faraone, Biederman, \& Mick, 2006).

Neuropsychological studies show that children with ADHD may have dysfunction in terms of a number of executive functions: reduced working memory, reduced process speed and difficulties with time, timing and motor skills (Faraone et al., 2015). Studies have also shown a delayed maturation in the cerebral cortex compared to peers (Faraone et al., 2015; Shaw et al., 2012). This is particularly evident in the prefrontal regions which are important for executive functions; attention and planning of motor skills (Faraone et al., 2015).

The causes of ADHD are a combination of hereditary and environmental factors, where heredity is considered to contribute $70-80 \%$. Examples of environmental factors include low birth weight, premature birth, smoking and alcohol abuse by the mother during pregnancy and exposure to environmental toxins that can interact in children genetically predisposed to ADHD (Faraone et al., 2015).

\section{Intellectual disabilities}

According to DSM-5 (American Psychiatric Association, 2013), ID is defined as a deficit in intellectual functioning (IQ < 70) combined with a deficit in adaptive functioning in at least one of three domains: conceptual, social, and practical. The conceptual domain includes language and literacy, concepts of money, time and numbers, and self-direction. The social domain includes interpersonal skills, social responsibility and social problem-solving. The practical domain includes activities of daily living, e.g. personal care, occupational performance and use of products involved in daily activities (American Association on Intellectual and Developmental Disabilities, 2010).

The global prevalence of people with ID is estimated to be about $1 \%$ and among adults about $0.5 \%$ (Maulik, Mascarenhas, Mathers, Dua, \& Saxena, 2011). Maulik et al. (2011) found a higher prevalence in low- and middle-income countries, in studies that did not use standard diagnostic systems and in studies with children and adolescents compared to adults.

Children with ID have slower cognitive development than children without disabilities, and the level of abstract thinking as an adult is lower (Kylén, 1986). People with ID have limitations in their executive functions (Danielsson, Henry, Ronnberg, \& Nilsson, 2010). It is well known that difficulties with abstract concepts such as the understanding of time concepts (Kylén, 1986; Owen \& 
Wilson, 2006) and a reduced working memory (Kylén, 1986) are common in children and adults with ID. This affects practical skills in activities of daily living (American Association on Intellectual and Developmental Disabilities, 2010). The diagnosis of ID is divided into three levels of severity: mild, moderate, and severe/profound (American Psychiatric Association, 2013). Difficulties in activities of daily living differ according to the level of ID, the demands from the environment and the activity performed.

Causes of ID differ and in more than half of cases the causes are unknown (Stevenson, Procopio-Allen, Schroer, \& Collins, 2003). The most common known causes are hereditary, or causes due to chromosome change, central nervous system diseases (CNS disease) or brain damage (American Psychiatric Association, 2013).

\section{Theoretical framework}

The theoretical bases for this thesis are the International Classification of Functioning, Disability and Health (ICF) and the Canadian Model of Occupational Performance and Engagement (CMOP-E). Both frameworks take a holistic view of health and occupation, and emphasize the dynamic interaction between the person, the environment and the occupation performed, which is in line with the focus of this thesis. Another reason for using these frameworks is the ambition to understand and emphasize participation/engagement. To improve and facilitate communication, some of the concepts used in this thesis are denominated using the ICF standardized language. ICF is a globally used classification system that enables understanding across different professionals. The dynamic interaction between the components and the fact that there is a specific participation component is also in line with the focus of this thesis. CMOP-E is used as an additional conceptual framework that provides a deeper explanation of the role of occupation and occupational performance. The special focus on client centeredness in CMOP-E is also applied in this thesis.

\section{International Classification of Functioning, Disability and Health}

ICF is based on a biopsychosocial model and provides a holistic view of health, integrating data from the biological, individual and social perspectives (World Health Organization, 2007). ICF is composed of the components body functions and body structures, activities and participation, environmental factors and personal factors (Figure 1). There is a dynamic interaction between the components. Health conditions can both affect the components and be affected by the components. Body functions are defined as "the physiological functions of body systems". Body structures are "anatomical parts of the body such as organs, limbs and their components". Activity is defined as "the execution of a task or action by an individual" and participation as "involvement in a life situation". Environmental factors and personal factors are contextual/background factors which may have an impact on the person and his or her health and health-related 
states. Environmental factors "make up the physical, social and attitudinal environment in which people live and conduct their lives". These factors can hinder or facilitate the person's performance. Personal factors are "the particular background of an individual's life and living, and comprise features of the individual that are not part of a health condition or health states".

ICF has shown to be too extensive for practical use, and less extensive versions "core sets" have therefore been developed recently. The version for children with ADHD aged 6-16 includes 55 categories (Bolte et al., 2018).

Figure 1.Interactions between the components in ICF (World Health Organization, 2007).

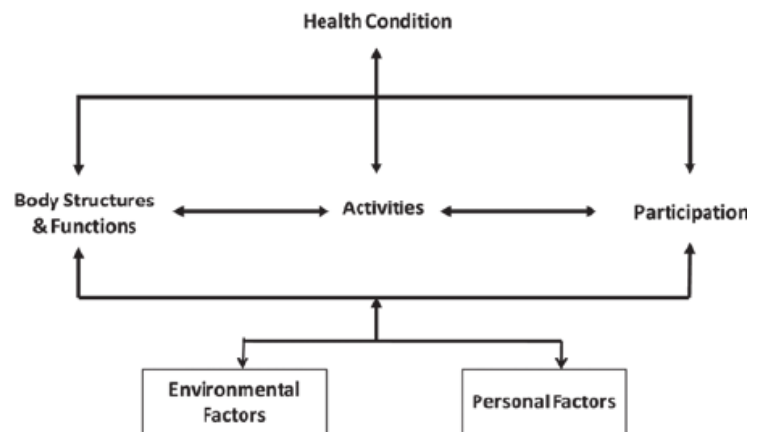

\section{Canadian Model of Occupational Performance and Engagement}

CMOP-E is an occupational model focusing on occupational performance and engagement (Polatajko, 2007). Theoretical influences come from humanistic, developmental and learning, and environmental theories. There are three components of CMOP-E: the person, the environment and the occupation (Figure 2).

Figure 2. The components and categories of CMOP-E (Polatajko, 2007).

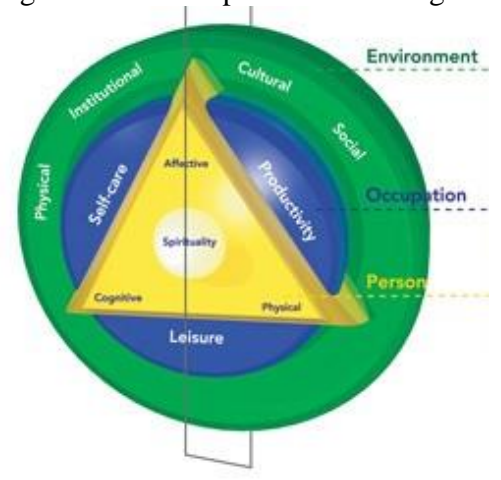


There is a dynamic interplay between the three components. The person is situated in the middle of the model. Three performance components make up the person: cognitive, affective and physical. At the core of the person is spirituality, "the essence of self", which is shaped and expressed through occupations. The person exists in the environment and this is where the occupation occurs. Environment is considered to be an important aspect influencing occupation. It is divided into four components: physical, cultural, institutional and social. Occupation is classified in three categories referred to as occupational purposes: self-care, productivity and leisure. Occupation is the way the person interacts with the environment. In CMOP-E, the focus is on client centeredness. Another core aspect of CMOP-E is the belief that the person has the ability to adapt and acquire skills. In the engagement component, the interest is not only in performing occupations but also in having occupations. Engagement is seen as an outcome of the dynamic interaction between person, occupation and environment.

\section{Daily time management and time processing ability}

In everyday life, adults, adolescents and children all have to deal with issues concerning time. Daily time management (DTM) refers to a person's ability to perform a cognitive plan and accomplish and finish everyday activities in the right order and within a certain time interval. Examples include carrying out morning chores in good time and hurrying up if needed. DTM is important in terms of becoming independent and autonomous, and performing everyday activities successfully (Davies, Stock, \& Wehmeyer, 2002; Janeslätt, Granlund, \& Kottorp, 2009). According to International Classification of Functioning, Disability and Health: Children and Youth Version (ICF-CY), two codes specifically define time in daily life: managing one's time (d2305) and adapting to time demands (d2306). Together, these can be referred to as DTM (Sköld \& Janeslätt, 2017). Both codes are defined in the activities and participation component (general tasks and demands). DTM is partially based on a person's cognitive function of TPA (Janeslätt et al., 2009). TPA development seems to follow the chronological age of children without disabilities (Bylholt, 1997; Janeslätt, Granlund, Kottorp, \& Almqvist, 2010). TPA develops during childhood and adolescence, starting with time perception, followed by time orientation and time management in typically developing (TD) children. Time perception (experience of time and durations of activities) and time orientation (telling the time and knowing which day and month it is) are basic levels of TPA and are necessary for time management (Janeslätt, 2012; Janeslätt et al., 2009). Time management is a superordinate concept to describe planning, ordering events in chronological sequences and allocating the amount of time for activities. Time management develops last and is part of the higher-level 
cognitive/executive functions. Prospective memory is included in time management and is needed to ensure that a behaviour stops and another begins at a specific time (Gillespie, Best, \& O'Neill, 2012). ICF-CY includes three codes related to TPA: experience of time (b1802), orientation to time (b1140) and time management (b1642). These codes are defined in the body functions component (experience of time and time functions, orientation functions and higher-level cognitive functions). Transferring the cognitive functions (TPA) into manage one's time in daily life (DTM) is a challenge and takes a lot of practice. According to ICF contextual factors as environmental factors and personal factors can hinder or facilitate a person's functioning (World Health Organization, 2007) (Figure 3).

Figure 3. Description of the relationship between Daily time management and Time processing ability, and their relationship to the components of ICF. Modified from Janeslätt (2009).

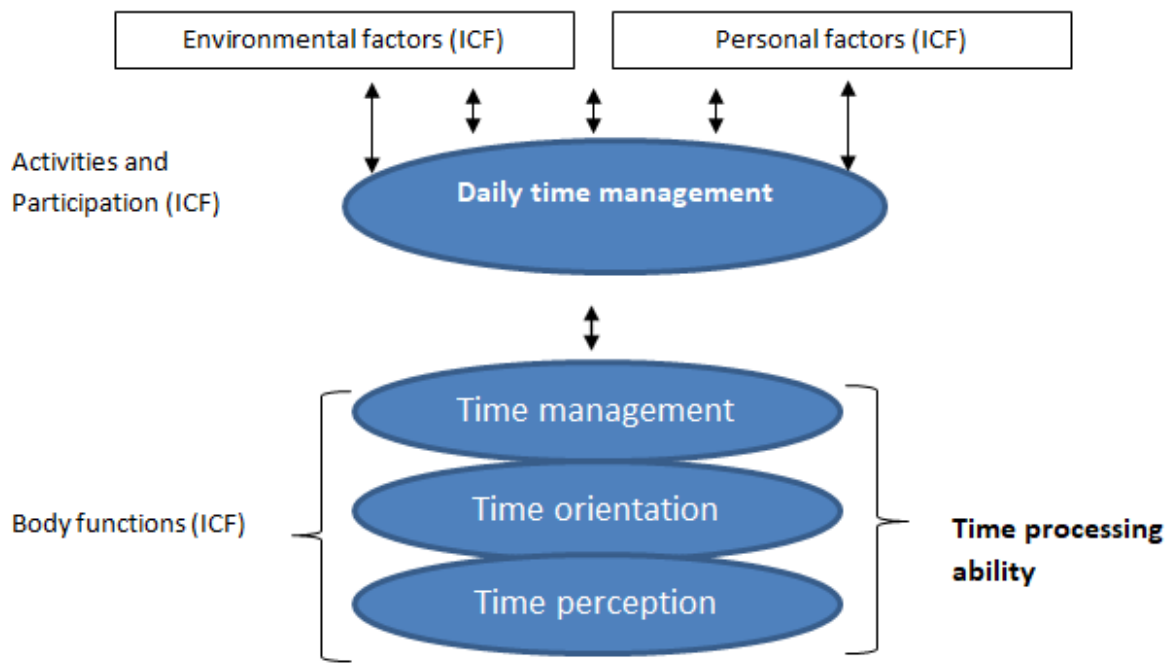

\section{Participation and autonomy}

According to ICF, participation is defined as "involvement in a life situation" (World Health Organization, 2007). Participation can be seen primarily as an interaction between the person and the environment, both social and physical. The environment can facilitate or hinder participation. Participation includes two dimensions: attending and involvement while attending (Granlund, 2013). According to Maxwell (2012), the frequency of attending is strongly related to the accessibility of the environment while the degree of involvement is related to how well adapted and acceptable the activity is for the person. Participation is often judged by other people, but as the concept of participation means that the 
individual's own will, motivation, goals and roles are important for the experience of participation, this leads to the individual having to assess his or her own participation (Björck-Åkesson, 2004).

An important factor for participation is a person's autonomy, which is suggested as a prerequisite for an individual's ability to participate in his or her current environment (Cardol, De Jong, \& Ward, 2002; Imms, Granlund, et al., 2016). High self-ratings of autonomy have been shown to be related to a high degree of self-rated participation (Almqvist \& Granlund, 2005; Eriksson \& Granlund, 2004) and good quality of life (Lachapelle et al., 2005). Personal characteristics such as autonomy and internal locus of control have been related to participation at school for children with disabilities (Almqvist \& Granlund, 2005). It has been shown that autonomy can facilitate participation, but is also shaped by participation (Imms, Adair, et al., 2016).

Cognitive impairment affecting TPA is not always visible, but can still lead to reduced autonomy and participation in everyday life. According to Cardol, De Jong \& Ward (2002), personal autonomy can have two dimensions: deciding what to do (decisional autonomy) and doing what one has decided (executional autonomy). Decisional autonomy loads heavily on cognitive functions, i.e. knowing one's capacity and preferences, knowing the demands of the activity, taking into account pros and cons, and finally deciding what to do and when to do it (Chan, 2002). Executional autonomy, according to Peny-Dahlstand et al. (2012), is likewise dependent on the ability to initiate, organize, adapt and proceed with the task until the goal is reached, i.e. observable executive functions. In their study of children with spina bifida (aged 6-14), children's levels of autonomy were strongly related to the performance of everyday activities, and in particular to activities depending on executive functions. Rosenberg (2015) also states that executive functions are vital for young children's independence and autonomy in daily life. In Janeslätt et al. (2010), children's self-rating of autonomy was related to their TPA, except for the youngest children (aged 5).

\section{People with ID and time-related difficulties in everyday life}

Children, adolescents and adults with ID have limitations in intellectual functioning and adaptive behaviour (Intellectual \& and Developmental Disabilities (AAIDD), 2010). They have deficits in conceptual skills, e.g. time skills, and in practical skills in everyday activities. It is well known that difficulties in abstract concepts such as understanding time (Kylén, 1986; Owen \& Wilson, 2006) are common in children, adolescents and adults with ID. Clinically, adults with ID in particular have had interventions directed to time deficits for a long time. Nevertheless, there are few studies on TPA and DTM for 
people with ID (Owen \& Wilson, 2006). In one of few studies on children with ID, the children made more errors in prospective memory than children without disabilities (Levén, 2007). They also had weaker time reproduction than the children without disabilities. Studies of adolescents and young adults with ID and time-related interventions are about training them to tell the time (Applegate, Rice, Stein, \& Maitra, 2008), prompting them to use an alarm to identify the time and initiate work-related activities independently (Dipipi-hoy, Jitendra, \& Kern, 2009), or using a portable schedule prompting system in vocational and daily living tasks (Davies et al., 2002). All these studies were carried out in experimental settings. It is shown in some studies that children, adolescents and adults with ID benefit from activity schedules (Koyama \& Wang, 2011) and time assistive devices (TADs) to enhance DTM (Arvidsson \& Jonsson, 2006; Granlund, Bond, Lindström, \& Wennberg, 1995; Janeslätt, Kottorp, \& Granlund, 2014; Söderstrom, Ostby, Bakken, \& Ellingsen, 2019) and TPA (Janeslätt, Kottorp, et al., 2014). To our knowledge, there is only one study where people with ID have reported their own experiences of using TADs (Arvidsson \& Jonsson, 2006).

\section{Children with ADHD and time-related difficulties in everyday life}

Children and adolescents with ADHD have been shown to have deficits in executive functioning, including planning (Abikoff et al., 2013; Barkley, 1997; Faraone et al., 2015). They also have problems in organizing materials and activities, time management and planning (OTMP) (American Psychiatric Association, 2013; Langberg, Epstein, \& Graham, 2008; National Board of Health and Welfare, 2014). Specific problems with time and timing have also been recognized in children with ADHD (American Psychiatric Association, 2013; National Board of Health and Welfare, 2014; Noreika, Falter, \& Rubia, 2013; Toplak, Dockstader, \& Tannock, 2006). Children with ADHD seem to have a different sense of time than typically developing (TD) children (Smith, Taylor, Rogers, Newman, \& Rubia, 2002). Their ability to discriminate and reproduce time intervals and to make retrospective time estimations has been shown to be impaired (Rubia, Halari, Christakou, \& Taylor, 2009; Toplak et al., 2006). Only one article was found investigating time-based prospective memory and the relation to time perception in children with ADHD (Mioni, Santon, Stablum, \& Cornoldi, 2016). Mioni et al. (2016) found that children with ADHD performed less precisely on time-based prospective memory tasks and used less efficient clock-checking strategies than TD children of the same age. This is in line with earlier research showing that children with ADHD or learning difficulties might have a TPA equivalent to that of younger children (Forer \& Keogh, 1971; Janeslätt et al., 2010). Children with ADHD have been shown to have a delayed maturation of the cerebral prefrontal regions that are important for 
executive functions, including time management (Faraone et al., 2015; Shaw et al., 2012). The consequences of time-related deficits in daily life are difficulties in automatizing routines, understanding the concept of time, achieving an overview of time, being on time for an appointment, starting and completing daily activities independently, planning and completing long-term projects, maintain goal-directed actions, understanding and using a calendar, and hurrying up if required (American Psychiatric Association, 2013; Barkley, 1997; Kofler et al., 2018; Langberg, Becker, Epstein, Vaughn, \& Girio-Herrera, 2013). This difficulties affects all aspects of life: daily routines and homework, school work, and social relations (American Psychiatric Association, 2013; National Board of Health and Welfare, 2014).

\section{Self-rated autonomy in children and young adults with ID and ADHD}

Autonomy in children and adolescents with disabilities has mostly been studied in a school context. The results show lower participation and self-rated autonomy in children with disabilities compared to children without disabilities (Eriksson \& Granlund, 2004; Eriksson, Welander, \& Granlund, 2007). In a study by Eriksson et al. (2007), 66 children aged between 7 and 12 with and without disabilities were observed at school over the course of one day, and were also interviewed about participation and asked to self-rate their autonomy. The results showed that children with disabilities, mostly children with ID, children with ADHD and children with motor impairment, had lower participation and self-rated autonomy compared to children without disabilities. In Eriksson \& Granlund's (2004) study of 959 children with and without disabilities aged 7 to 17 , children with disabilities (including children with ID) rated their participation and autonomy in school activities lower than children without disabilities. Studies in which children with ADHD and children with ID self-rate their autonomy outside the school context are sparse. We only found two studies in which children self-rated their autonomy in everyday activities. In a study by Janeslätt et al. (2009), 118 children aged 6-11 with different diagnoses (including ADHD and ID) self-rated their autonomy. Parents' ratings of DTM and measurements of TPA were also conducted. The results showed a significant relationship between self-ratings of autonomy, parents' ratings of DTM and the children's TPA. The same pattern was shown in Janeslätt et al. (2010), where children with $(n=77)$ and without $(n=$ 89) diagnosis and aged 5 to 10 self-rated their autonomy. As in the previous study, autonomy and DTM were related to the children's TPA. Children with disabilities were found in different clusters, showing diversity in TPA, DTM and autonomy that was not explained by diagnosis. 


\section{Time-related interventions}

The primary treatments for children and adolescents with ADHD are psychosocial and/or pharmacological treatment (National Board of Health and Welfare, 2014; National Institute for Heath and Care Excellence, 2009). The Swedish National Board of Health (National Board of Health and Welfare, 2014) recommends assistive technology for cognition (ATC) as a complement to other interventions for children with ADHD. Interventions for children with ID often take the form of activity schedules (Koyama \& Wang, 2011).

Interventions can be divided into three parts: advocacy, compensation and remediation (McColl, Law, \& Stewart, 2015).

\section{Advocacy}

Advocacy is often in the form of psychoeducation, aiming to provide information about the (ADHD) diagnosis and its treatment and offering an opportunity to discuss strategies for managing (ADHD) symptoms in daily life. Psychoeducation directed at parents of children with ADHD has been shown to achieve good effects, especially regarding parents' understanding of their child's difficulties, and to improve interactions between parents and children (Langberg, Epstein, Urbanowicz, Simon, \& Graham, 2008), as well as reducing ADHD symptoms (Ferrin et al., 2016). However, we found no study regarding psychoeducation focusing on difficulties managing time in daily activities.

\section{Compensation}

Compensation intervention aims to compensate for a cognitive disability. The purpose is to enhance independence when performing activities, to support participation in everyday life and to create the opportunity to build a larger social network (Jacobsson, 1999). Cognitive support compensates for the cognitive deficit and includes adaptations in the physical environment, a cognitive supporting approach from the psychosocial environment, supporting routines and strategies, and different kinds of devices (Wennberg B., 2016). ATC has been developed within the last 20 years. Gillespie et al. (2012) state in their review that the most frequent use of ATC is to assist with the executive functions of time management and organization and planning. TADs are ATCs aimed at compensating for deficits in time management, orientation to time and experience of time. Examples include reminders/alarm clocks, day/weekly (activity) schedules or step-by-step schedules with text or pictures, and timers visualizing time graphically as dots that decrease in number or a surface that decreases in size (Gillespie et al., 2012; International Organization for Standardization, 2019; Koyama \& Wang, 2011; Lequia, Machalicek, \& Rispoli, 2012; Söderstrom et al., 2019). TAD may be high-tech, e.g. apps for smartphones and electronic planning devices, but can also be low-tech, consisting of paper and pictures (Gillespie et al., 2012; International Organization for Standardization, 
2019; National Board of Health and Welfare, 2014). Greater independence, a sense of self-control and increased DTM have been reported for children, adolescents and adults with autism, acquired brain injuries, developmental disabilities, intellectual disabilities and psychiatric illness (Adolfsson, Lindstedt, \& Janeslatt, 2015; Charters, Gillett, \& Simpson, 2015; Gillespie et al., 2012; Gillette \& DePompei, 2004; Janeslätt, Kottorp, et al., 2014; Leopold, Lourie, Petras, \& Elias, 2015; Lindstedt \& Umb-Carlsson, 2013; Söderstrom et al., 2019). Most studies have focused on adults with acquired brain injuries (Gillespie et al., 2012). Since ATC is a relatively new research field, there is no consensus regarding definitions and different concepts are applied to the same types of device, e.g. cognitive assistive devices (CADs).

\section{Remediation}

Training programmes to target deficits in organizational, time management and planning (OTMP) have been well studied in children and adolescents with ADHD (Evans, Owens, \& Bunford, 2014). OTMP interventions might be performance oriented, based on the child not having the motivation to perform the skill, and the intervention consists of parents and teachers setting specific individual daily goals for children, prompting and monitoring them to ensure they achieve these goals. The Parents and Teachers Helping Kids Organize (PATHKO) intervention is performance oriented, and sessions are primarily focused on parents and teachers. PATHKO resulted in significantly better organizational functioning compared to a waiting list control group (Abikoff et al., 2013). Skill-based OTMP interventions are based on the child not having the skill, and the intervention therefore focuses on helping children to learn new tools and routines. Examples include Organizational skills training (OST) and the Homework, Organization, and Planning System (HOPS). In the OST intervention, children learn to record assignments and expiration dates, organize school papers into binders and use checklists. The intervention includes individual sessions for the children. Parents and teachers should prompt, praise and reward skills use. OST is designed for children at elementary school. The HOPS intervention is based on a similar model of training to OST, but for older children (at middle schools). Children work with a coach and in a similar way to the OST intervention, but they also learn to plan homework completion. The results indicate significantly better parent ratings for organization, but teacher ratings do not show any significant effects (Evans, Langberg, Egan, \& Molitor, 2014). In a meta-analysis of organizational interventions for children and adolescents with ADHD, OTMP training leads to moderate improvements as rated by teachers and significant improvements as rated by parents (Bikic, Reichow, McCauley, Ibrahim, \& Sukhodolsky, 2017). The need to investigate individual differences between children and to individualize the intervention period in the OTMP programmes is highlighted (Breaux, Langberg, Bourchtein, et al., 2019; Breaux, Langberg, Molitor, et al., 2019). However, all OTMP 
interventions have mainly focused on organization skills in a school context and in school work, e.g. organizing the material needed in the school situation and doing homework on time (Bikic et al., 2017; Gureasko-Moore, Dupaul, \& White, 2006; Langberg, Epstein, Becker, Girio-Herrera, \& Vaughn, 2012; Langberg, Epstein, Urbanowicz, et al., 2008), all based on parents' and/or teachers' ratings. We found no study with OTMP interventions for children with ADHD focused specifically on time management in daily activities outside the school context, and no study where children's self-ratings were used.

Research on training programmes focusing specifically on time is spare. In a single-case design study an adult with ID practised comparing an analogue clock face with a digital one (Applegate et al., 2008). In a recent randomized controlled trial (RCT), Janeslätt et al. (2019) evaluated a new intervention programme 'My Time' to improve low level of TPA (time perception) in 61 children aged 10-17 with mild or moderate ID. The intervention was performed in groups during ordinary special classes over a period of eight weeks. Children measured the duration of daily activities with a specially designed stopwatch, visualizing the time in dots. The children then documented the duration (the number of dots) of every activity in a log book and compared and discussed their documentation. The results implied a significant increase in TPA in the intervention group compared to the control group.

\section{Rationale for the thesis}

Several ATCs, especially TADs, have been developed during the last 20 years. Still, this is a relatively new area of research. People with ID are the target groups in Sweden who have had access to these devices for the longest time, but few studies have been carried out on the effects of their use and users' perceptions of how these devices affect activity and participation. Knowledge about this may also be useful for people with other diagnoses.

Knowledge of the importance of TPA for achieving functional everyday routines for people with neurodevelopmental disorders is still limited. Children and adolescents with ADHD have been shown to experience difficulties with time, but few studies show more specifically the difficulties and strengths these children have with TPA and DTM, and how they differ from children with ID and TD children. There is a need to describe and compare TPA in children with ADHD compared to TD children and children with ID, and how deficits in TPA could affect everyday activities. Also differences in self-rated autonomy are of interest for these groups. By gaining better knowledge of these children's problems, adequate treatment methods can be developed and introduced.

Today, compensational interventions are mainly available for children, adolescents and adults with ID, and pharmacological and psychoeducational treatments for children and adolescents with ADHD. Time-related interventions for children and adolescents with ADHD are in their infancy. In Sweden, 
children and adolescents with ADHD have only had access to TADs to a limited extent (Adolfsson, 2012). The same applies to training time processing skills. There are still no randomized controlled studies or systematic studies for the target group (de Joode, van Heugten, Verhey, \& van Boxtel, 2010; Gillespie et al., 2012) regarding the effectiveness of this kind of intervention in everyday life. By evaluating a new combined intervention form based on three components psychoeducation for parents and school staff, occupational therapy including TAD and time skills training - we are paving the way for treating children with ADHD. It is hoped that this combined intervention form can also be used for other groups of children with time and planning difficulties, e.g. children with ID and autism. 


\section{OVERALL AIM}

The overall aim of this doctoral thesis is to investigate daily time management and time-related interventions aimed at enhancing participation in everyday life among school-age children and young adults with neurodevelopmental disorders.

\section{Aims}

\section{Study I}

To describe experiences of participation, i.e. having opportunities to influence, have control and make decisions when using cognitive assistive devices in daily activities, from the perspective of people with intellectual disabilities.

\section{Study II}

To investigate how a multimodal intervention, consisting of training in time processing ability and compensation with time assistive devices, affects time processing ability and daily time management in children with attentiondeficit/hyperactivity disorder aged 9-15, compared with psychoeducational intervention only.

\section{Study III}

To investigate daily time management, time processing ability and self-rated autonomy in everyday activities in children aged 9-15 with attentiondeficit/hyperactivity disorder, compared to children with intellectual disabilities and typically developing children.

\section{Study IV}

To examine the outcome of a multimodal time-related intervention designed to support children with attention-deficit/hyperactivity disorder aged 9-15 in achieving their occupational performance goals and to compare children's ratings of outcome with parents' ratings. An additional aim is to identify occupational performance goals, related to time, chosen by children and their parents. 


\section{METHOD}

This thesis is based on four studies that use qualitative and quantitative methods to investigate daily time management, time processing ability, self-rated autonomy, outcomes of time-related interventions and the experience of participation when using time assistive devices. Participation has permeated the research process and the intervention.

An overview of the study design, participants, data collection and data analysis is presented in Table 1.

Table 1. Summary of the thesis studies I-IV; participants, design, data collection and data analysis.

\begin{tabular}{|c|c|c|c|c|}
\hline Study & Participants & Design & $\begin{array}{l}\text { Data collection and } \\
\text { instruments }\end{array}$ & Data analysis \\
\hline I & $\begin{array}{l}\text { Nine adolescents and } \\
\text { young adults aged } \\
17-37 \text { with ID. }\end{array}$ & Qualitative. & $\begin{array}{l}\text { Semi-structured } \\
\text { interview guide with } \\
\text { open-ended and follow- } \\
\text { up questions. }\end{array}$ & $\begin{array}{l}\text { Phenomenological } \\
\text { analysis. }\end{array}$ \\
\hline II & $\begin{array}{l}38 \text { children and } \\
\text { adolescents aged 9- } \\
15 \text { (19 in each group) } \\
\text { with ADHD. }\end{array}$ & $\begin{array}{l}\text { Randomized } \\
\text { controlled trial. } \\
\text { Data collection at } \\
\text { baseline and at follow- } \\
\text { up. }\end{array}$ & $\begin{array}{l}\text { Demographic questions. } \\
\text { Structured assessment } \\
\text { (KaTid). } \\
\text { Children's self-reporting } \\
\text { (Time-self rating). } \\
\text { Parent questionnaire } \\
\text { (Time-Parent scale). } \\
\text { Study protocol. }\end{array}$ & $\begin{array}{l}\text { Descriptive statistics. } \\
\text { Differences between the } \\
\text { control and intervention } \\
\text { groups at follow-up } \\
\text { were analysed with } \\
\text { ANCOVA. } \\
\text { Sensitivity analysis of } \\
\text { drop-outs. }\end{array}$ \\
\hline III & $\begin{array}{l}\text { 141 children and } \\
\text { adolescents aged 9- } \\
\text { 15; } \\
47 \text { with ADHD ( } 38 \\
\text { from study II), } 47 \\
\text { with ID and } 47 \\
\text { without } \\
\text { neurodevelopmental } \\
\text { disorders. }\end{array}$ & $\begin{array}{l}\text { Descriptive, } \\
\text { comparative and cross- } \\
\text { sectional design. }\end{array}$ & $\begin{array}{l}\text { Structured assessment } \\
\text { (KaTid). } \\
\text { Children's self-reporting } \\
\text { (Self-rating of } \\
\text { Autonomy). } \\
\text { Parent questionnaire } \\
\text { (Time-Parent scale). }\end{array}$ & $\begin{array}{l}\text { Descriptive statistics. } \\
\text { Group comparisons with } \\
\text { one-way analysis of } \\
\text { variance (ANOVA) with } \\
\text { Tukey post-hoc tests for } \\
\text { multiple comparisons. } \\
\text { Cluster analysis with } \\
\text { Ward's method of } \\
\text { agglomeration. }\end{array}$ \\
\hline IV & $\begin{array}{l}27 \text { children and } \\
\text { adolescents from } \\
\text { study II. }\end{array}$ & $\begin{array}{l}\text { Quasi-experimental, } \\
\text { comprehensive and } \\
\text { descriptive design. } \\
\text { Outcome measure at } \\
\text { baseline and at follow- } \\
\text { up. }\end{array}$ & $\begin{array}{l}\text { Demographic questions. } \\
\text { Structured assessment } \\
\text { (KaTid). } \\
\text { Client centred outcome } \\
\text { measure (COPM). } \\
\text { Study protocol. }\end{array}$ & $\begin{array}{l}\text { Descriptive statistics. } \\
\text { Comparative analysis } \\
\text { with non-parametric } \\
\text { methods } \\
\text { (Wilcoxon signed rank } \\
\text { test). } \\
\text { Each goal coded to ICF. }\end{array}$ \\
\hline
\end{tabular}




\section{Participants}

\section{Study I}

In study I, nine people aged 17-37 (mean age 24.7) with ID were selected by purposive sampling. The inclusion criteria were mild ID (Kylén, 1986), being able to communicate verbally and having been prescribed a CAD within the last two years. The participants were two men and seven women. Four of the participants lived with their parents, four lived in their own apartment with support from staff and one participant lived independently in an apartment. Five participants worked at a daily activity centre, two were at school and two were waiting to get a job.

\section{Study II}

The participants in study II were recruited, as a consecutive sampling, from three child and adolescent psychiatric clinics and one children's habilitation service in Sweden between September 2012 and March 2015. The inclusion criteria were a diagnosis of ADHD, age 9-15 and parent-reported difficulties with DTM, despite medication for ADHD and ten points or more on a clinical rating of 15 statements related to problems with DTM. The exclusion criteria were autism spectrum disorder, IQ $<70$ and language barriers (e.g. not being able to answer questionnaires in Swedish). This resulted in 38 children (28 boys and 10 girls), who were randomly allocated to an intervention $(n=19)$ or control group $(n=$ 19). The mean age of the intervention group was 11.7 (range 9.2-15.1) and the mean age of the control group was 11.1 (range 8.6-13.5).

\section{Study III}

The participants in study III were children with ADHD $(n=47)$, children with ID $(n=47)$ and TD children $(n=47)$, aged $9-15$. The mean age in the sample was 11.5 (range 8.6-15.7). Most of the children were boys $(n=96,68 \%)$. The children with ADHD were participants from study II, including both children from the intervention group and children from the control group, investigated before the intervention. The children with ADHD were matched pairwise with a child with ID and a TD child based on gender and chronological age. The children in the comparison groups were samples drawn from a database compiled by certified occupational therapists (OTs) participating in courses for KaTid certification. All children with ID were diagnosed as having mild or moderate ID and three of them with comorbidity (autism spectrum disorder, cerebral palsy, and impairment of hearing and language impairment). None were diagnosed with ADHD. The TD children were recruited as a convenience sample from the participants in courses for KaTid certification among the normal population, self- 
reported by their parents as being healthy and having no diagnosis, and thereafter included in the database. In total there were 141 participants.

\section{Study IV}

The participants were children with ADHD $(n=27)$ from study II, including both children from the intervention group and children from the control group who were later offered intervention. A complementary inclusion criterion for study IV was the completion of the COPM instrument at baseline and at follow-up. This resulted in 17 boys and 10 girls with a mean age of 11.7 (range 9.1-15.1).

\section{Procedure and data collection}

To enhance participation in the procedure and data collection phase, a great deal of effort was put into offering concrete and understandable information to the participants about the studies. The choice of data collection methods, with interviews and self-ratings for the children, adolescents and young adults as a complement to proxy-reports and a structured assessment, is in line with this.

In study I, participants were recruited through OTs working in youth and adult habilitation service in central Sweden. The OTs were informed about the study via professional conferences, by email and by telephone, and were asked to relay an easy-to-read letter containing information about the study to potential participants. The letter included a request for permission to phone the person. Those who agreed to participate were contacted by the first author (BW), and a convenient time and location for the interview, e.g. habilitation service centre, the participants' home or workplace, was agreed for each participant.

In studies II, III and IV, participants with ADHD were recruited from three child and adolescent psychiatric clinics and one children's habilitation service in Sweden between September 2012 and March 2015. The clinics represented large cities, small towns and sparsely populated areas. Parents of the children with ADHD who met the criteria were asked to participate in the study during normal monitoring visits to the child and adolescent psychiatric clinics or children's habilitation service. Information about the study's purpose and structure was provided orally, and in writing in the form of a booklet containing brief information. Parents were also asked to appoint someone (preferably a teacher or another member of school staff) to act as the child's coach. The parents who agreed to participate received written invitations to personal visits for the purpose of data collection, with one invitation for the parents and an adapted version for the child, accompanied by a consent form.

Data collection took place at the outpatient clinic over the course of one or two visits. During the visit(s), the parents met a trained OT for an interview to identify and prioritize everyday issues that restricted or impacted on the child's occupational performance in everyday activities (using the COPM) and to 
respond to the Time-Parent scale questionnaire. They then met an assistant to answer demographic questions. The child met a research assistant/BW to respond to the self-rating of Autonomy, and met the trained OT for an assessment (KaTid) and to respond to the Time-Self rating questionnaire. If needed, the child was offered help by reading or explaining the questions in the self-rating questionnaires. During a second baseline visit, children in the intervention group (study II) and all children offered intervention (study IV) decided - together with their parents - on goals for intervention using COPM. The children and their parents then rated the current level of the children's occupational performance and their satisfaction with this performance separately. After 24 weeks, a followup was carried out using the same assessments (data used in studies II and IV). For data collection at follow-up, the children and their parents met a trained OT who was not involved in the intervention.

In study III, children with ID and TD children were made up of samples drawn from a database compiled by certified OTs participating in courses for KaTid certification. KaTid certification includes a number of KaTid assessments of children with and without disabilities, and the data is held in a database. Certification also includes data collection from the children's self-rating of Autonomy and Time-Parent scale questionnaires. The children with ID in this database are selected by participating OTs working in children's habilitation services with children with mild or moderate ID. TD children from this database are recruited as a convenience sample by the participants in the courses for KaTid certification from among the normal population, self-reported by their parents as being healthy and having no diagnosis.

\section{Intervention}

The intervention was designed to be multimodal, based on guidelines for interventions for children and adolescents with ADHD (National Board of Health and Welfare, 2014; National Institute for Heath and Care Excellence, 2009), and had three components: advocacy, compensation and remediation (McColl et al., 2015). Both the intervention and control groups were exposed to advocacy in the form of a one-day psychoeducation session for parents and coaches. The additional intervention (compensation and remediation) lasted for 10 to 12 weeks.

\section{Advocacy}

Prior to the intervention, all the children's parents and coaches (see below) were offered advocacy in the form of psychoeducation. This psychoeducation was provided as a basis for parents and coaches to increase their understanding of deficits in the child's TPA and how this could affect the child's DTM, to motivate the parents and coaches to facilitate the child's participation in the intervention, and - for ethical reasons - to offer at least some intervention to all 
children. The psychoeducation lasted for six hours and was given in groups. The focus was on lectures about DTM and the development of TPA in TD children compared with children with ADHD. It also included information about the consequences of TPA deficiencies in daily activities, how to find strategies to compensate for these consequences, and how to support children with deficiencies in time-related skills. The psychoeducation included group discussions, sharing experiences and discussing strategies. The instruction was manualized and the co-author was responsible for the content and conducted all sessions.

\section{Compensation}

The compensation component was tailored to the individual needs of the child, based on the occupational performance goals chosen by the child and his or her parent(s), and on the child's time processing ability (Gillespie et al., 2012; Janeslätt, Kottorp, et al., 2014; McColl, 2003). The OT worked deliberately to facilitate the child's active participation in the goal setting and planning of the intervention together with the parent(s). During an initial session, the OT met the child and the parent(s) to give feedback from the assessment findings. After that the compensation intervention included three or four treatment sessions with the OT (each lasting about 90 minutes) over a period of ten to twelve weeks, with both parent(s) and child participating. The focus was on working with the occupational performance problem by identifying individual activitycompensating strategies for the child, structuring the physical environment and manufacturing or prescribing TADs (McColl, 2003).

Examples of compensating strategies included establishing and maintaining morning and evening routines, establishing daily routines to check the next day's activities and spreading homework over smaller units of time. Examples of structuring the physical environment included organizing sportswear so that it was easy to find and take to school, and making sure clocks were visible in every room of the home.

Prescribing or manufacturing TADs included choosing an adequate TAD depending on the chosen goal, the child's TPA and the environmental conditions, introducing the TAD and teaching the child to use it, and subsequently following-up on its use. The TADs used in this intervention were both low-tech (e.g. step-by-step schedules showing how to perform an activity in a timely order, and daily, weekly or annual schedules on plastic-coated paper with pictures showing the planned activities in timely order) and high-tech (e.g. TADs including timers visualizing time as dots that decrease in number to show time passing, electronic day schedules with pictures and smartphone apps for reminding and planning). 


\section{Remediation}

The remediation component, consisting of time-skills training, was documented in a manual. Each child had a coach (chosen by the parents) to support them in performing the time-skills training. The majority of these coaches were school staff (often teachers or school assistants). This set-up, with coaches supporting children to train often and regularly, was inspired by skills-based OTMP programmes (Evans, Owens, et al., 2014; Langberg et al., 2012; Langberg, Epstein, \& Graham, 2008).

The time-skills training was presented in the form of challenging tasks. The concept of challenging tasks was inspired by 'My time' (Aberg, 2012), a programme designed to help children with ID develop their TPA by systematically collecting experiences of time through visualizing, documenting and communicating how long different everyday activities take. In the present study, the challenging tasks were specially developed for children and adolescents with ADHD (by co-author and BW). They consisted of 13 tasks of increasing complexity, starting with the child training his or her perception of time (challenges 1-3), followed by a training precursor to time management (challenges 4-8) and time orientation (challenge 9), and later on training in time management (challenges 10-13). Most of these challenging tasks were focused on everyday activities to make it easier for the children to transfer their experiences to activities of daily living. All the challenging tasks were gathered in a binder, together with instructions for the child on how to perform the tasks. This was supplemented with information for the coach on how to support the child in the different tasks. Every child was supposed to complete ten different tasks. Three of the 13 tasks were exchangeable, depending on the age and maturity of the child. The child was supposed to carry out the challenging tasks for 20 minutes a day, receiving support from the coach at a short meeting one to three times a week during the training period.

Prior to the remediation, all coaches met the OT, together with the parent(s), to obtain feedback from the assessment findings and instructions for the timeskills training. All coaches were also offered supervision by the OT at two sessions during the training period, as a group session or an individual session by telephone.

Examples of the child's participation in the intervention included goalsetting, allowing the child to choose which goal they would start with, in what order the morning schedule details should be presented and with which pictures, and where in the home the digital calendar should be positioned. The instructions in the challenging tasks were also directed to the child, and the child was allowed to choose which activities they wanted to measure. 


\section{Instruments}

\section{Semi-structured interview guide}

In study I, data collection was conducted via semi-structured interviews. An interview guide with four concrete questions and follow-up questions was designed (Kvale, 1997). These questions were organized in a logical time perspective, focusing on the respondent's experience of participation using their CAD over a period of time. The interview started with two questions concerning the present experiences of using CAD: "Tell me about your CAD (or the name of the device)" and "What do you do if you need help with your CAD?" Examples of follow-up questions included: "When do you use your CAD?", "What do your family and friends think about your CAD?" and "Who helps you if you need help with your CAD?" The questions then moved on to the respondent's experiences before the CAD was prescribed: "What was it like before, when you didn't have a CAD?" Follow-up questions included: "Did you perform the same activities before compared to now?" and "Did you decide more or less about things before?" Finally, the respondents were asked how they thought they would use the CAD in the future. To enhance memory and communication, the respondents were asked to show how they used their CADs. Validity during the interviews was ensured through the information provided being checked continually with the interviewees (Kvale, 1997).

In all the interviews except for two, only the respondent and the interviewer were present at the interview. One of the respondents asked for a relative to attend interview and another respondent wanted the prescribing OT to attend the interview. These two respondents wanted social support to help them feel comfortable in the unfamiliar situation. The respondents agreed to the interviews being recorded digitally.

\section{The Kit for assessing Time processing ability (KaTid)}

KaTid (Janeslätt, 2012) is an instrument for assessing time perception, time orientation and time management for children with a developmental age of 5-10 years (KaTid-Child) and adolescents with a developmental age of 10-17 years (KaTid-Youth). The child responds to questions and performs practical exercises, such as setting a timer for a fixed time and placing picture sequences in the correct order. This instrument is interdisciplinary and the testing is performed by a trained professional person, e.g. an OT. KaTid-Child and KaTid-Youth have been shown to have good validity and reliability with children and adolescents, with and without disabilities, in measuring the same construct and measuring change (Janeslätt, 2012; Janeslätt, Kottorp, et al., 2014). KaTid-Child has been validated and tested for internal consistency in children with and without disabilities - the Cronbach Alpha was 0.78-0.86 (Janeslätt, Granlund, Alderman, \& Kottorp, 2008; Janeslätt et al., 2009). 
In this thesis, KaTid was used in studies II, III and IV. In study II, KaTid was used as a before and after measurement, and in study III as a comparative measurement between the groups and as a base for the cluster analysis. In study IV, KaTid was used to describe the participant's time processing ability. Both KaTid-Child and KaTid-Youth were used in this thesis, depending on the child's developmental age. KaTid-Child was used for six children with ADHD older than 10 years and for fourteen children with ID. KaTid-Youth was used for all TD children.

\section{The Time-Parent scale}

Parents use the Time-Parent scale to rate their children's DTM: understanding concepts of time, managing time and adapting to time demands (Janeslätt et al., 2008; Janeslätt et al., 2009). There are two versions, one for children aged 5-10 and one for adolescents aged 10-17. Both versions consist of 12 statements rated on a Likert frequency/agreement scale, with four response alternatives ranging from "Never/I don't agree at all" (1p) to "Always/I completely agree" (4p). There is also a "Don't know" (0p) option. The statements in the two versions capture the same ability but are set to different degrees of difficulty and are customized according to the different age ranges. The Time-Parent scale has been validated and tested for internal consistency, for children and adolescents with and without disabilities, with a Cronbach Alpha of 0.79-0.86. It has been found to be psychometrically sound and significantly correlated with TPA as measured by KaTid (Janeslätt et al., 2008; Janeslätt et al., 2009).

In this thesis the Time-Parent scale was used in study II and III. In study II, it was used as a before and after measurement, and in study III as a comparative measurement between the groups.

\section{The Time-self rating instrument}

Time-self rating is designed to capture children's own perceptions of DTM (Sköld \& Janeslätt, 2017). It contains 21 statements concerning DTM and seven items concerning strategies, and has a Likert scale with four frequency response alternatives ranging from "Never" (1p) to "Always" (4p). The instrument is validated on children aged 10-17 $(n=83)$ with disabilities using Rasch analysis. The results indicate that 21 items of the Time-Self rating fitted into a unitary construct measuring DTM, and reliability was high (0.82) yielding a separation value of 2.15, constituting good psychometric properties (Sköld \& Janeslätt, 2017).

In this thesis the 21 items measuring DTM were employed in the Time-self rating and the instrument was used in study II as a before and after measurement. 


\section{The self-rating of Autonomy}

Children use the self-rating of Autonomy sub-scale of the instrument "Children's participation in school, students' assessment forms" (Almqvist \& Granlund, 2005; Eriksson \& Granlund, 2004) to rate their autonomy. This scale is an adapted short version of the ARC self-determination scale (M. Wehmeyer \& Kelchner, 1995), in which the autonomy items are based on Sigafoos et al. (1988). The self-rating of Autonomy can capture the experience of participation according to ICF-CY (Almqvist \& Granlund, 2005; Eriksson \& Granlund, 2004). There are two versions, one for children aged 7-12 and one for adolescents aged 13-17. Children rate their autonomy in everyday activities or situations that they usually do or decide on by themselves, based on 23 (children's version) or 30 (adolescents' version) statements. The items are divided into the following sections: daily routines, interacting with people, recreational and leisure choices, community involvement, and personal style. The adolescents' version has an additional section: education and planning for my working life. It has a Likert response scale for frequency: "I do not do it" (1p), "Sometimes" (2p), "Often" (3p) and "Always" (4p).

The two autonomy versions have been validated and tested for internal consistency with a Cronbach Alpha of 0.62 for children aged 7-12 and 0.78 for adolescents aged 13-17 (Eriksson \& Granlund, 2004). To allow children who need a shorter questionnaire to evaluate their autonomy, there is an even shorter version: Autonomy short (Janeslätt et al., 2008), based on 14 items with the same four response alternatives as the other versions. All seven items capturing autonomy in daily routines from the original children's version are included, as well as some items concerning choices and interacting with people. Autonomy short has been shown to be psychometrically sound in construct validity (Janeslätt et al., 2008), and it has been demonstrated that a version using the first 12 items can be used to measure self-rated autonomy just as well as the longer versions (Janeslätt et al., 2010).

In this thesis, the self-rating of Autonomy was used in study III as a comparative measurement between the groups. Due to the convenience recruitment of participants, all three versions were used.

\section{The Canadian Occupational Performance Measure (COPM)}

COPM (Law et al., 2005) is a client centred outcome measure to enable clients to identify, validate and prioritize everyday issues that restrict or impact their performance in everyday living and it provides a basis for setting individual intervention goals. The instrument has a broad focus on occupational performance in all areas of life, including self-care, leisure and productivity. COPM consists of two parts: a semi-structured interview part identifying occupational activities and a structured estimating part intended to detect changes in a client's self-perception of occupational performance and satisfaction with performance over time. The client identifies his or her performance problems and 
then rates the actual performance and satisfaction with each performance problem using a ten-point Likert scale. The scale for performance ranges from "Cannot perform it at all" (1p) to "Can perform it extremely well" (10p), and the scale for satisfaction ranges from "Not satisfied at all" (1p) to "Extremely satisfied" (10p). Changes pre- and post-intervention scores for performance and satisfaction can be determined separately, and an increase of two or more points indicates a clinically significant change (Taylor et al., 2007). The reliability and validity of COPM have been studied and are clearly acceptable (Cup, Scholte op Reimer, Thijssen, \& van Kuyk-Minis, 2003; McColl, Paterson, Davies, Doubt, \& Law, 2000). The clinical usefulness has been studied with positive results (Wressle, Eeg-Olofsson, Marcusson, \& Henriksson, 2002).

In this thesis, COPM was used in study IV as a tool for identifying occupational performance problems, and as a before and after measurement.

\section{Data analysis}

\section{Study I}

Data were analysed using a phenomenological approach (Giori, 1985; Malterud, 1993; Malterud \& Midenstrand, 2009). The interviews were transcribed verbatim to obtain raw data. The analysis was carried out in four steps (Giori, 1985). First, all the material was read through to get a general impression. Brief notes were made of points that were particularly relevant to the purpose of the study. The second step included identifying meaning units. Every interview transcript was read through to identify meaning units connected to the purpose. Four themes emerged during step three, based on the content of the meaning units. Further, the coded material was read to summarize, condense and reduce the content into 12 categories related to each theme. In the last step, quotations from the participants were chosen to illustrate the different categories. To increase the credibility of the study, the analysis was discussed with faculty colleagues (Krefting, 1991).

\section{Study II}

Demographics were analysed using descriptive statistics (gender, medication, mean age, living situation, parent's national origin, parent's marital status and parent's education, as well as TPA and DTM at baseline). Data were analysed for differences in TPA and DTM between the control and intervention groups at the 24-week follow-up. A change score was calculated for KaTid, Time-parent scale, and Time-self rating by subtracting the baseline score for each child from the follow-up score. ANCOVA was used with the difference score as the dependent variable; group, gender and living situation as fixed factors and age as a covariate. Effect size (ES) was used to analyse the magnitude of the differences in TPA and DTM. This was calculated using Cohen's $d$ with effect size $d=0.2-0.5$ 
representing a small effect, $\mathrm{d}=0.5-0.8$ a medium effect and $\mathrm{d} \geq 0.8$ a large effect (Cohen, 1988). A sensitivity analysis of the drop outs was also carried out.

\section{Study III}

Variable-based analysis was used to analyse differences in TPA, DTM and selfrated autonomy between the three groups. Group comparisons were made using one-way analysis of variance (ANOVA) with Tukey post-hoc tests for multiple comparisons (Wright, London, \& Field, 2011). A bootstrapping procedure with 1000 replicated Cls was conducted to correct for subgroup heterogeneity and small sample size. Reported p-values were adjusted accordingly (Wright et al., 2011). An in-between analysis of effect size (ES) for the different groups was calculated using Cohen's $d$, with ES $d=0.2-0.5$ representing a small effect, $d=$ $0.5-0.8$ a medium effect and $d>0.8$ a large effect (Cohen, 1988).

To compare the data for all children despite using different versions of the measurements with different sum scores, some adjustments were necessary. Regarding TPA, raw points on KaTid-Child were converted into raw points for KaTid-Youth using a transformation scale (Janeslätt, 2012). Additionally, the percentage of theoretical maximum score based on the versions used in KaTid, Time-Parent scale and the self-rating of Autonomy was computed respectively. ANOVA analysis was then performed on each version of KaTid, of Time-Parent scale and of the self-report of Autonomy.

To take into account the diversity among the children with the same diagnosis and to look for individual relationships between TPA, DTM and autonomy, a hierarchical cluster analysis was carried out using Sleipner 2.0 (Bergman \& El-Khouri, 2002) with Ward's method of agglomeration. The data used in the cluster analysis were the four subscales of KaTid. Based on the fact that different versions of KaTid with different sum scores on each subscale were used for the children, all subscale sums needed to be converted into the percentage of sum scores. In this study, the following criteria were used to identify the number of clusters: (i) a homogeneity coefficient of less than 1.00 (preferably <0.50), (ii) a percentage of the total explained error sums (ESS) of at least 67\%, (iii) a distinct break in the scree plot indicating a large increase in ESS and the number of clusters to retain before the increase, and (iv) split sample replicability through a total rerun of the cluster analysis on a random half of the sample of at least 0.30 , the mean in ASED between the clusters in the two solutions (Bergman, Magnusson, \& El-Khouri, 2003) using the Sleipner module Random.

\section{Study IV}

Demographics (age, gender, medication, living situation and TPA) were analysed using descriptive statistics. To allow for a comparison of the children's TPA, independent of which version of KaTid was used, raw scores were converted into scale scores (Janeslätt, 2012). The number of participants corresponding to the 
mean range and to the ranges of $\pm 1 \mathrm{SD}$ and $\pm 2 \mathrm{SD}$ from the reference range of typically-developing children was calculated (Persson, Janeslatt, \& PenyDahlstrand, 2017).

Individual mean values for the ratings of occupational performance and satisfaction were calculated. Because of the small sample, a comparative analysis with non-parametric statistics using the Wilcoxon signed rank test was used. An analysis was carried out of the ratings for performance and satisfaction scores between the child's and the parent's ratings at baseline and at follow-up. To examine the outcome of the intervention, a comparative analysis of the differences in scores for performance and satisfaction at baseline and at followup was undertaken for the child and for the parent(s). Effect size was calculated using Cohen's $d$, with effect size $d=0.2-0.5$ representing a small effect, $d=0.5-$ 0.8 a medium effect and $d \geq 0.8$ a large effect (Cohen, 1988). The proportion of children and parents indicating an increase of two or more points when rating performance and satisfaction with performance was also calculated. This magnitude demonstrates a clinically meaningful change in COPM scores (Law et al., 2005). Each goal, reflecting an occupational performance problem, was coded to ICF (World Health Organization, 2007). All goals were mapped independently by BW and two co-authors as content experts. We used the itemlevel content analysis mapping methods described by Cieza (2005). If the goal contained more than one concept, each concept was mapped to a corresponding ICF code. All TADs used to reach the occupational performance goals of the children were also mapped to ICF, as were the 13 challenging tasks.

In studies II, III and IV, the data were analysed using the Statistical Package for Social Sciences (SPSS) version 24.0, 25.0, and 26.0 (SPSS Inc. Chicago, IL, USA), selecting a significance level of 0.05 and a confidence interval of $95 \%$. In study III, Sleipner 2.0 was used in the cluster analysis (Bergman \& El-Khouri, 2002).

\section{Ethical considerations}

Ethical approval for the studies was granted by an advisory statement from the Local Ethics Committee in Jönköping (study I, D-nr 2007-1542-31/5), the Regional Ethical Review Board in Linköping for the children with ADHD (studies II, III and IV, D-nr 2012/166-31), and the Local Ethics Committee in Uppsala for children with ID and the TD children (Study III, D-nr 2005/032). Written informed consent was obtained from all parents of children and adolescents under the age of 18 in the studies and from the adult participants in study I. Written informed consent was also collected from older children with ADHD participating in studies II, III, and IV. The ethical guidelines stipulated by the Declaration of Helsinki (World Medical Association of Helsinki, 2008) guided the research process. 
In all studies included in this thesis, the ethical considerations were considered as being of particularly importance since the participants had cognitive problems which affected their understanding of information (study I) or the participants were children (studies II, III, and IV). To meet the ethical guidelines and to enhance participation (for the participants) in the research process, a letter/booklet in easy-to-read format with information about the study was sent prior to the interview (study I) or the first visit (studies II, III and IV). During the interview, or the first meeting, information was repeated including the purpose of the study, the right to withdraw from the study, anonymization and publication in scientific papers. Information about data collection, the randomization process and the length of the intervention was given to the parents in writing and to the children in an adapted version (studies II and IV). The standard of confidentiality was established by altering participants' names and not using quotations that could potentially reveal participants' identities (study I). 


\section{RESULTS}

\section{Study I. Participation when using CAD - from the perspective of people with ID}

The majority of the respondents stated that they participated more in the activities they wanted to do or had to do, and they used the cognitive assistive device (CAD) in all areas of life: to take care of themselves, at work or school, and during their leisure time. Their experiences of participation using CADs in daily activities resulted in four different themes: the usefulness of CAD, patterns of activities, the effect on health and roles and social barriers. The respondents described the usefulness of CAD at present time in terms of having an overview of time and activities, being reminded, starting to do activities independently, knowing how much time is left until the next activity and knowing how to handle money when shopping. They also described their visions about using the CAD in the future. Under the theme patterns of activities, some respondents performed fewer activities than before, while others performed more activities or the same number of activities. One respondent's overview of activities in the CAD showed a busy schedule, resulting in her doing fewer activities and feeling a better balance between rest and activities. For some respondents the use of CAD resulted in more activities such as managing the CAD and activities that they did not perform previously, since they did not had access to CADs e.g. going shopping by themselves and working more independently. The respondents described an effect on health and roles. The feeling of having more control led to health benefits, such as not being as stressed and no longer having stomach ache. The experience of having a new, more adult role identity is confirmed by the respondents. The adult role was expressed in terms of being more independent and making independent decisions. However, there were some social barriers. Participation was sometimes restricted by the attitudes of staff. Several respondents expressed their frustration at not being allowed to upload activities in their CAD by themselves, or not getting the necessary information about upcoming events. They also mentioned that one's own family and friends' attitudes could hinder participation in activities. Some respondents chose not to use the CAD when visiting family and friends for fear of showing that they need a CAD or that the CAD's beeping will be irritating. 


\section{Study II. Effectiveness of time-related interventions in children with ADHD aged 9-15 years: a randomized controlled study}

All children's global TPA scores increased, but children in the intervention group $(n=19)$ increased their TPA significantly more compared to the control group $(n$ $=19)(p=.019)$. There was a statistically significant increase in the two basic sublevels of time processing ability - time perception $(p=.046)$ and time orientation $(p=.010)-$ and an increase (but not statistically significant) compared to the control group in the time management subscale. The parents in the intervention group rated their children's DTM as significantly more improved ( $p=.011$ ) compared to the parents of children in the control group. However, according to the children, there was no statistically significant improvement in their DTM. The psychoeducation for parents and school staff about TPA and DTM was appreciated, but was not enough in itself to increase children's TPA and DTM significantly. The number of challenges accomplished varied between three and ten (mean: eight). All children received one to four TADs (mostly one or two). The majority of TADs were intended to compensate for deficits in time perception or time orientation. A visual timer was one example of a TAD compensating for deficits in time perception, and electronic day schedules, or weekly or annual schedules on plastic-coated paper were examples of TADs to compensate for time orientation. A few children received TADs to compensate for deficits in time management: an online calendar synchronized to the child's own mobile phone and a prescribed mobile calendar app, adapted for the child (Figures 4 and 5).

Figure 4. Examples of TADs compensating for time perception and for time orientation. (Photo by Kersti Sköld. Printed with permission.)

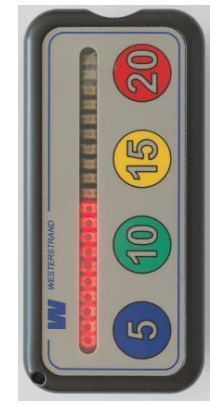

Visual timer

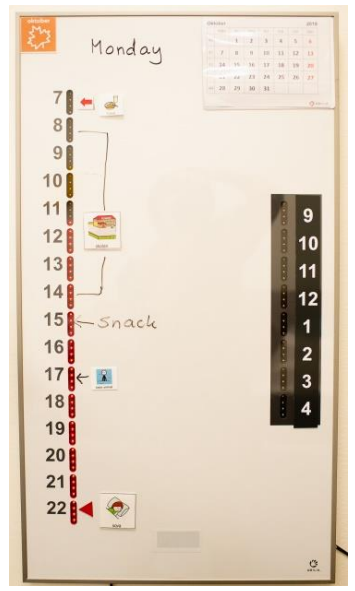

Electronic day schedule
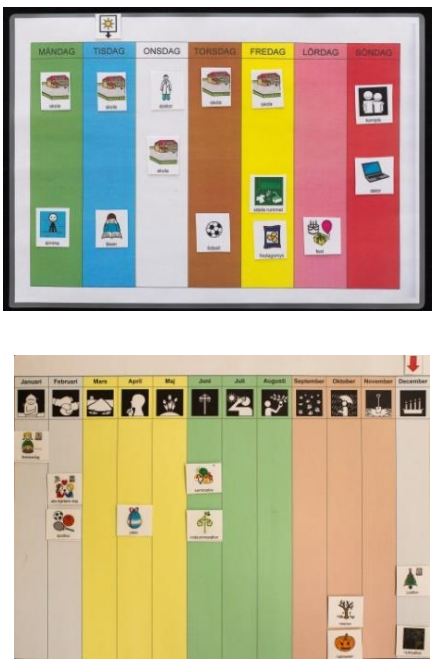

Weekly and annual schedules 
Figure 5. Example of a TAD compensating for time management. (Photo by Kersti Sköld. Printed with permission.)

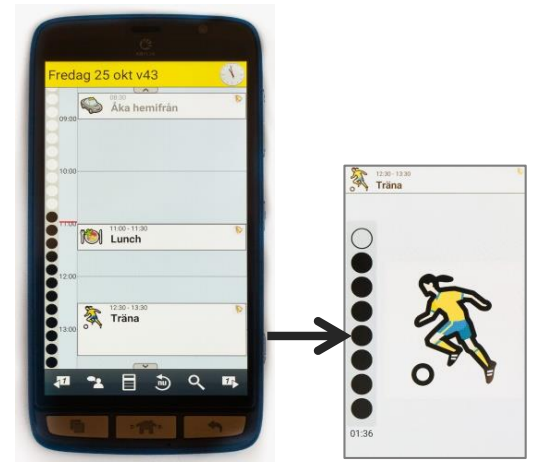

Prescribed mobile calendar-app visualizing time left to the activity "training".

\section{Study III. DTM and autonomy in school-age children with ADHD, ID, and TD children show different patterns}

There were statistically significant differences between the groups according to TPA $(p<.001)$, DTM $(p<.001)$ and self-rated autonomy $(p<.001)$. TD children had the highest scores for DTM, as well as for TPA and self-rated autonomy. As a group, children with ADHD had statistically significantly higher scores for TPA and self-rated autonomy compared to children with ID, while children with ID had statistically significantly higher scores for DTM compared to children with ADHD.

The cluster analysis resulted in four clusters showing patterns of TPA from skilled in all levels of TPA to difficulties in all levels of TPA. Nevertheless, the overall patterns of TPA were the same with the highest scores being for time perception, and decreased ability for the subsequent higher levels of TPA. The differences in competence within the two groups of children with neurodevelopmental disorders were high, and could not be explained by the chronological age of the child.

DTM as rated by parents is almost the same in all clusters, with the exception of the cluster containing children who have difficulties at all levels of TPA, which has the lowest score of DTM. There were statistically significant differences in autonomy, as rated by the children themselves, between the clusters. The patterns of autonomy followed the level of TPA. Clusters with high scores of TPA also have higher scores of autonomy. 


\section{Study IV. Occupational performance and outcome of time-related interventions for children with ADHD - children and parents ratings}

The identification of occupational performance goals according to ICF showed that most occupational performance goals were a combination of the body functions component and the activities and participation component (57\%). Approximately half of these goals were linked to experience of time (b1802) and undertaking multiple tasks (d220), just under half were linked to orientation to time (b1140) and undertaking multiple tasks (d220), and the remaining goals were linked to time management (b1642) and undertaking multiple tasks (d220). Twenty-eight percent of the occupational performance goals could be attributed only to the activities and participation component and were linked to carrying out daily routines (d230). A slightly smaller proportion of the occupational performance goals were a combination of the body functions and environment factors $(12 \%)$ and were linked to orientation to time (d1140) and products and technology for personal use in daily living (e115). Only 3\% of the occupational performance goals could be attributed solely to body functions, and were linked to orientation to time (b1140).

Children and their parents agreed on one to four goals $(M=2.5)$, which reflected occupational performance problems defined by the parents and the children. In total there were 72 goals. Most goals decided by the children and their parents involved daily routines and knowing what will happen during the day, the coming week and the coming month (see above). All the children received one to four TADs, usually one or two. The majority of the TADs were designed to compensate for deficits in time perception or time orientation. Four children (15\%) received TADs to compensate for deficits in time management. Some TADs were used as an intervention for more than one goal, for example a visual timer to facilitate morning routines as well as knowing the time duration for other activities. Other goals had to be achieved using more than one TAD, such as a visual timer and a step-by-step schedule. 
Figure 6. Example of TADs compensating for time perception. (Photo by Kersti Sköld. Printed with permission.)
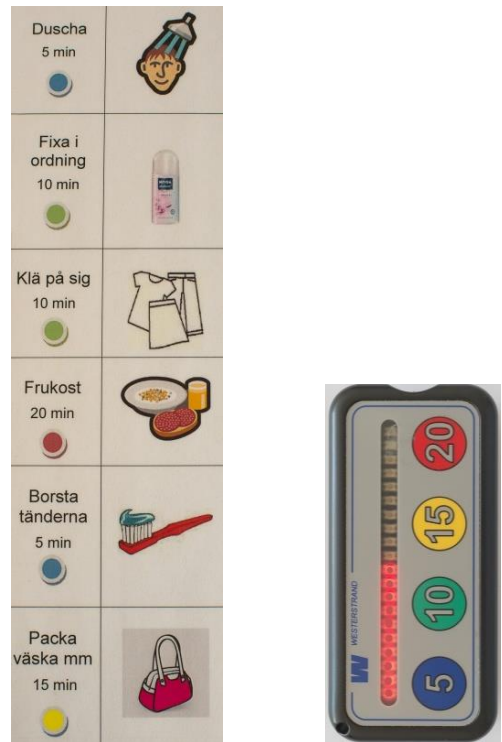

Step-by-step schedule (morning routine) combined with a visual timer.

The majority of both parents and children rated occupational performance at follow-up higher than at baseline. The difference is statistically significant, according to both the children's ratings $(p=.001)$ and their parents' $(p<.001)$. Slightly more than half of the children $(52 \%)$ and half of the parents $(50 \%)$ estimated a change of two points or higher, which is seen as a clinically significant change. Children and their parents also rated satisfaction higher at follow-up than at baseline, with statistically significant differences for the children's ratings $(p=.001)$ and for their parents' $(p=.001)$. More than twothirds of both children $(70 \%)$ and their parents $(71 \%)$ rated the satisfaction change as two points or more. In general, children rated their occupational performance and satisfaction higher than their parents, both at baseline and at follow-up. This difference was statistically significant.

In conclusion, the results from study IV indicate that children and adolescents with ADHD benefit from time-related interventions consisting of time skills training and time assistive devices in reaching their occupational performance goals. The results also show that the occupational performance goals decided on by the children and their parents mostly refer to daily routines, and to performing daily activities while relying on time perception and time orientation abilities. 


\section{GENERAL DISCUSSION}

The overall aim of this thesis was to investigate DTM and time-related interventions aimed at enhancing participation in everyday life among school-age children and young adults with neurodevelopmental disorders. The five major findings were as follows. First, the fact that young people with ID experience increased participation in daily activities using CADs. Second, participation and autonomy in performing activities can be dependent on TPA. Third, children and adolescents with ADHD and those with ID may have specific difficulties with DTM, TPA and autonomy. Fourth, a combination of compensation and remediation increased DTM and TPA in children and adolescents with ADHD. Fifth, participation could be used as both a means and a goal in intervention with children, adolescents and young adults with neurodevelopmental disorders.

\section{Summary of findings}

\section{Increased participation in daily activities using CADs}

In study I, young adults with ID described their experiences of using CADs, mostly TADs, and that CADs supported them in becoming more autonomous, making decisions by themselves, performing their desired occupations independently, and participating more in daily activities. This shows increased independence, a finding that contributes to the growing body of knowledge about adults with ID using CADs (Arvidsson \& Jonsson, 2006; Mechling, 2011; Söderstrom et al., 2019; M. L. Wehmeyer, Palmer, Smith, Davies, \& Stock, 2008). However, participation restrictions were reported (study I) due to environmental factors, the attitudes of staff or relatives towards participation, or the participant's or social network's attitude towards the use of CAD. The importance of environmental factors in terms of facilitating or hindering participation is stated in the ICF (World Health Organization, 2007) which also notes that a supporting social network may facilitate the use of a cognitive assistive device (Adolfsson, Lindstedt, Pettersson, Hermansson, \& Janeslatt, 2016). To take advantage of this knowledge, a psychoeducation day about TPA and DTM was offered to parents and coaches in studies II and IV. The psychoeducation day proved popular, and has probably contributed towards the results in studies II and IV. However, this needs to be examined in further studies.

The voices of the users in study I, also provide a deeper understanding of participation in activities when using CADs, expressed in terms of being more autonomous and making decisions on their own. However, when comparing the 
results from study I to Arvidsson and Jonsson (2006) study, some differences emerge. Arvidsson and Jonsson's (2006) results highlighted independence and autonomy as two different phenomena and suggested that independence does not always lead to increased autonomy, while in the present study making decisions by themselves and independently performing occupations were part of the experiences of increased autonomy and participation.

\section{Participation and autonomy in performing activities can be dependent on TPA}

The results from study III in which children self-rated their autonomy, using a structured measurement including statements of both decisional and executional autonomy, showed that a low degree of TPA was associated with low scores for self-rated autonomy. This is in accordance with the findings from a study of younger children aged 5-10 years, with and without a diagnosis (Janeslätt et al., 2010). Peny-Dahlstrand et al, (2012) also found that high observed executive functions were related to high levels of self-rated autonomy in children with spina bifida. In study III, both children with ADHD and children with ID had lower levels of autonomy compared to TD children. The fact that both decisional and executive autonomy are dependent on cognitive functions has been noted in a number of studies (Cardol et al., 2002; Chan, 2002; Peny-Dahlstrand et al., 2012). As autonomy could be a prerequisite for participation (Cardol et al., 2002; Imms, Granlund, et al., 2016), self-rated autonomy was of interest in this study. These results highlight the importance of interventions supporting cognitive functions, including TPA, as well as compensation interventions in children and adolescents and ID with ADHD in order to enhance their autonomy and thereby support their participation in everyday life.

\section{Specific difficulties in TPA, DTM and in autonomy for children with ADHD and children with ID compared to TD children}

\section{The overall pattern of TPA is the same as for TD children}

The cluster analysis in study III revealed four clusters of children with different levels of TPA. Although there were statistically significant differences in diagnosis between the clusters there were no signs of differences in the overall pattern of TPA. This indicates that children with ADHD and ID have the same overall pattern of TPA development compared to TD children, but for some of these children this occurs at a slower pace. This result is in line with a previous study indicating that children with disabilities might develop TPA at a slower pace, with a larger variance in functioning in TPA within the group, than for TD children (Janeslätt et al., 2010). The overall developmental pattern of TPA is in line with previous studies which suggest a development of TPA for TD children starting with the perception of time, followed by time orientation and 
subsequently time management (Bylholt, 1997; Janeslätt et al., 2008). The same pattern was found in a study including younger children, aged 5-10 years, with and without disabilities (Janeslätt et al., 2010).

This thesis includes the first research (study III) ever to investigate patterns of TPA based on the four levels of TPA; time perception, time orientation/concepts, time orientation/objective time and time management. One interesting finding was that all clusters showed a distinct difference in decrease between the subscales time orientation/concepts and time orientation/objective time. This indicates that there are sublevels within time orientation, and that time concepts are easier to manage than understanding what objective time is. This is in line with Janeslätt et al. (2010), who raised the issue of time orientation as two different strands.

A suggestion based on the results from this thesis is that the model of TPA, as described by Janeslätt (2009) could be developed further by dividing the level of time orientation into two sub-levels (objective time and concepts), to enhance the understanding of the concept of TPA (Figure 7).

Figure 7. Describing the relationship between DTM and TPA, and their relationship to the components of ICF. The level of time orientation divided into two sub-levels, objective time and concepts. Modified from Janeslätt (2009).

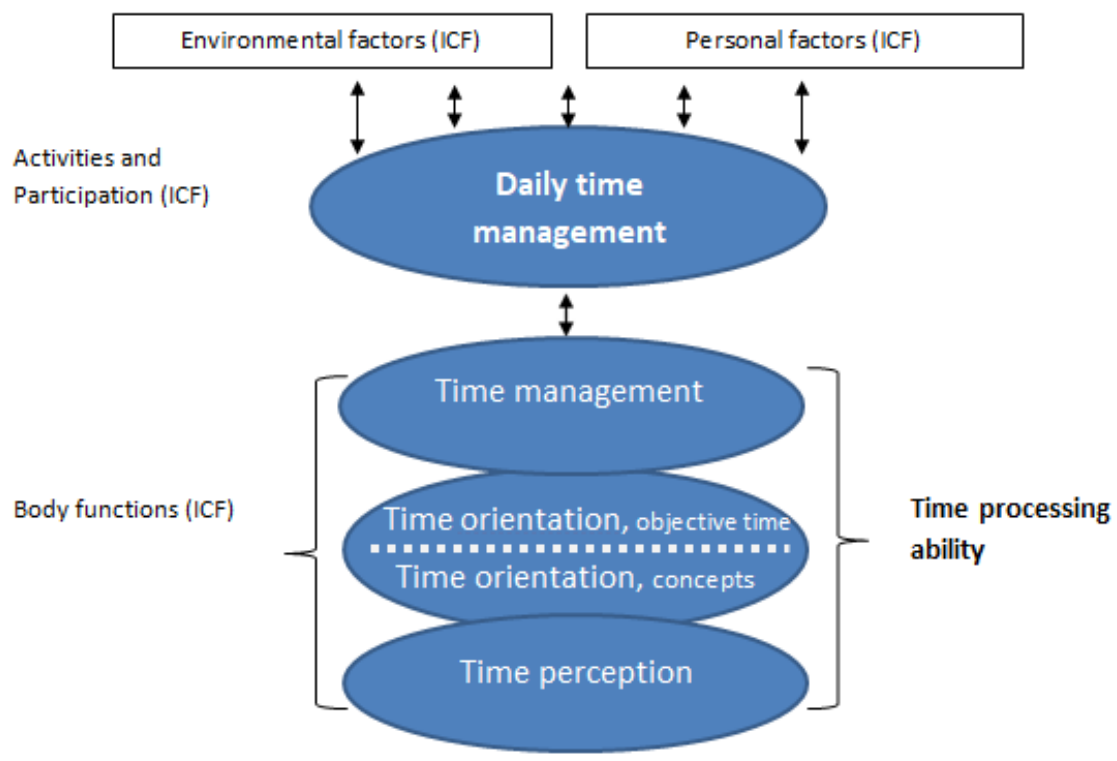




\section{Specific difficulties in TPA in children with ID and children with ADHD}

The results from study III show that both children with ADHD and those with ID had statistically significantly lower scores for TPA compared to TD children. This is in accordance with studies showing difficulties for individuals with ID in terms of understanding time concepts (Kylén, 1986; Owen \& Wilson, 2006), prospective memory (Levén, Lyxell, Andersson, Danielsson, \& Rönnberg, 2008), in performing activities in daily life (American Association on Intellectual and Developmental Disabilities, 2010; Janeslätt, Kottorp, et al., 2014). The results that also show lower scores for TPA in children with ADHD are in accordance with experimental studies of time perception (Rubia et al., 2009; Toplak et al., 2006), studies of prosepectory memory tasks (Mioni et al., 2016) and studies showing difficulties in executive functions e.g time mangement (Abikoff et al., 2013; Barkley, 1997; Faraone et al., 2015). However, the fact that children and adolescents with ADHD may have difficulties with the whole construct of TPA, including time perception, time orientation and time management, has not been presented in earlier research.

\section{Differences in TPA between the children}

The cluster analysis in study III showed diversity in levels of TPA, from children who have difficulties at every level of TPA to children who are skilled at every level. The diversity in TPA, which is not explained by age, for children with ADHD and for children with ID is interesting and indicates that not all children with ADHD and not all those with ID have the same degree of deficits in TPA. According to the DSM-5 (American Psychiatric Association, 2013) ADHD and ID can be divided into different levels of severity. The importance of viewing ADHD as a heterogeneous condition is pointed out by Wahlstedt et al. (2009) and by Willfors et al. (2014), who suggest that ADHD represents a "quantitative extreme on a continuum". This may support the findings in this thesis that the construct of TPA could be diverse and not explained by age.

\section{Relationship between TPA and DTM}

In study III, parents of children with ADHD rated their children's DTM as low, and even lower than that of children with ID who had, as a group, the lowest TPA compared to children with ADHD and TD children. This is contrary to a study by Janeslätt et al. (2009) where a high level of TPA was shown to be correlated with a high degree of DTM. In this study the children were younger (6-10 years) and children with other disabilities were also participating. The occupational performance goals, based on occupational performance problems, chosen by children with ADHD and their parents (study IV) also showed difficulties in performing activities related to all levels of TPA: perception of time (in durations of activities), orientation to time and time-management. According to their chronological age the participating children were supposed to be able to manage activities that require abilities relating to perception of time 
and time orientation, but this was not the case. These results also indicate that children with ADHD may have both deficits in cognitive functioning regarding TPA and specific problems in daily activities related to time. This is in accordance with studies showing a delay in maturation in the prefrontal cortical regions, which are important for executive functions, including time management, in children with ADHD (Faraone et al., 2015; Shaw et al., 2012). The present thesis adds knowledge to the intervention studies showing problems with organizing and planning school activities (Abikoff et al., 2013; Langberg, Epstein, \& Graham, 2008), and overall adaptive functioning (Lindblad et al., 2013) among children with ADHD.

\section{Relationship between TPA and self-rated autonomy}

In study III, children with ADHD had, as a group, a lower mean score for autonomy than TD children. In the cluster analysis the patterns of autonomy seemed to follow the level of TPA. This is in line with the results obtained by Janeslätt et al. (2010) for children aged 5-10 with and without a diagnosis. The higher a child's TPA, the higher they self-rated their autonomy. Peny-Dahlstrand et al. (2012) also found that high observed executive functions were related to high levels of self-rated autonomy in children with spina bifida. A number of studies (Cardol et al., 2002; Chan, 2002; Peny-Dahlstrand et al., 2012) have found that both decisional and executive autonomy are dependent on cognitive functions. The fact that children with ID in study III, who had the lowest scores for TPA, also had the lowest scores for self-rated autonomy is in agreement with this. The lower levels of TPA in children with ADHD and ID in study III, compared to TD children, could therefore be an explanation for the lower scores on self-rated autonomy compared to the TD children. The fact that autonomy is suggested to be a prerequisite for participation (Cardol et al., 2002; Imms, Granlund, et al., 2016) highlights the importance of interventions supporting cognitive functions, including TPA, in children with ADHD and ID in order to enhance their autonomy and thereby support their participation.

\section{Time-related interventions increase TPA and DTM in children and adolescents with ADHD}

In this thesis a new time-related intervention directed at children with ADHD and those with difficulties with DTM was designed and evaluated (studies II and IV). The results provide the first evidence of the effectiveness of the intervention. The children in study II improved their TPA significantly more compared to the comparison group. Still, the ES was smaller than that found by Janeslätt et al. (2014) where TPA increased strongly. One explanation could be the differences in the intervention period (six months in Janeslätt et al. compared to three months), in diagnosis (only 17\% were children with ADHD in Janeslätt et al.), and in age (younger children aged six to 11 in Janeslätt et al.). The larger ES in 
TPA in Janeslätt et al. (2014) might indicate that introducing TADs at a younger age was an advantage.

The children also increased their DTM compared to the control group and the ES was high (study II). The improvement in the intervention group is consistent with the results from Janeslätt et al.(2014). In addition, the children with ADHD in study IV showed an improvement in DTM and increased in their occupational performance and satisfaction according to their occupational performance goals. One interesting finding is that children's and parents' ratings move in the same direction, towards higher ratings, but children's ratings are at a higher level both at baseline and at follow-up. Studies of children's and parents' estimations of the child's health-related quality of life shows that these estimations do not always match (Matza et al., 2013) but the best agreement is found in physical functioning and performance competence (e.g. climbing stairs and doing housework) compared with their children's emotional or social functioning (Eiser \& Varni, 2013; Hemmingsson, Olafsdottir, \& Egilson, 2017).

The intervention in studies II and IV was based on compensation, with a treatment session provided by an OT, and remediation where the children performed time skills training with the support of a coach. The benefit of compensation with TADs is consistent with previous studies showing that children, adolescents and adults with different cognitive diagnoses (mostly acquired brain injury) enjoy greater independence and participation when using TADs (Adolfsson et al., 2015; Charters et al., 2015; Gillespie et al., 2012; Gillette \& DePompei, 2004; Janeslätt, Kottorp, et al., 2014; Leopold et al., 2015; Lindstedt \& Umb-Carlsson, 2013). In the intervention studies, II and IV, most TADs were used to visualize how long it took to perform an activity (with dots) and to show a timely order in which to do things (schedules with pictures and/or text), i.e. compensating for time perception and time orientation. For some children the TADs helped them to visualize planning and also had a reminder function, i.e. they compensated for time management. The evidence for compensational effect from TADs for TPA in persons with cognitive deficits has been shown in earlier studies (Gillespie et al., 2012; Lindstedt \& Umb-Carlsson, 2013). Additionally, based on the findings in this thesis, a question arises, of whether the use of TADs to visualize time and the timely order of steps in an activity, might also compensates for deficits in the executive functions of inhibition, since information is visible and can help to maintain attention. This fits well with an example in Diamond (2013), where the use of visual cues helped young children to remember an instruction and improved their inhibitory control performance. It is also in line with Willfors et al. (2014) who suggested that there is a greater possibility of positive treatment results concerning planning and inhibitory control in comparison with other areas of executive functions with higher degree of genetic influence .

The remediation component evaluated in this thesis is the first programme to focus on time-skills training in children and adolescents with ADHD. The 
findings are in line with Janeslätt et al. (2019), were adolescents with ID performed time skills training with similarly challenging tasks, but on a more concrete level. The positive effects of children training with a coach in a natural environment are in accordance with training programmes focusing on OTMP for homework assignments for children with ADHD (Evans, Owens, et al., 2014; Langberg J, 2011; Langberg et al., 2012).

The length of the intervention period, 10-12 weeks, with closely repeated sessions in studies II and IV, was appreciated by both parents and the OTs delivering the compensation component.

Before the intervention (and before the randomization in study II) the parents and coaches were offered a psychoeducation session. A combination of psychoeducation and compensation with TAD can be highly effective in children with developmental disabilities (Janeslätt, Kottorp, et al., 2014). However, the results from the RCT study (study II) showed that the children in the control group did not increase their TPA or DTM markedly even though their parents received psychoeducation that focused especially on time issues. This result indicates that psychoeducation alone is not enough to improve TPA and DTM in children with ADHD. Children who have difficulties with DTM despite medication probably need interventions that more specially target time and planning difficulties, together with training and compensation using TAD. Nevertheless, previous studies of psychoeducation have shown good effects on parents' understanding of the child's difficulties and improved interaction between parents and children (Langberg, Epstein, Urbanowicz, et al., 2008). In accordance with this, and the positive evaluations from parents and coaches participating in the psychoeducation (studies II and IV), it is suggested that psychoeducation for parents and stakeholders who come into contact with children with time-related difficulties should be a stepping stone for further timerelated interventions. The need for education about time and compensatory interventions directed at stakeholders who are supposed to support adults with ID is also seen in study $\mathrm{I}$.

\section{Participation used as both a means and a goal in the research process}

In this thesis participation has permeated the research process and the intervention both as a means and as a goal (Creek \& Lawson-Porter, 2007; Kjellberg, Kahlin, Haglund, \& Taylor, 2012). In order to follow the Declaration of Helsinki and the ethical guidelines, with a special focus on autonomy, (Beauchamp \& Childress, 2013), there has been a great emphasis in the present studies on trying to adapt the information in line with the participant's needs. In study I the aim was to investigate the experiences of participation using CADs. Asking the users themselves for their opinions and experiences gives a deeper understanding of the lived experiences of participation and should therefore be a driving force in occupational therapy (Polatajko, 2007; Townsend \& Polatajko, 2013). 
The Declaration of Helsinki (World Medical Association of Helsinki, 2008) states that participating in a research study must be voluntary, and that the intended participants must be informed about the aims of the study, the design and methods, the anticipated benefits and the potential risks. Because of the participants' cognitive disorders (study I) and low age (studies II, III, IV) the challenge was to achieve this in a way that the participants could understand. To facilitate the information process, information was given in an easy-to-read format (study I) or a booklet (studies concerning children with ADHD) containing the purpose of the study, the method and duration, as well as examples of time devices and the researchers' affiliations. Information was also provided orally. There was one invitation for the parent and an adapted version for the child, accompanied by a consent form (including an adapted version for the child). The consent form for children stated that they could withdraw their consent at any time and without any explanation. Some children (read parents) did so, but we do not know whether the children remembered that they had the opportunity to withdraw and for whether these who might have wanted to do so, to actually had the courage to do so. In order to concretize the amount of time that the participants were assumed to spend in the research study and to concretize the randomization process, a structured timetable specially developed for this study was shown and given to the child and the parents.

Children have a clear right to be involved in decisions that concern them. In recent years, the right to participation in care has been strengthened by legislation governing social services, health care and dental care (National Board of Health and Welfare, 2015). There is a fundamental right for children to express their views and to be listened to and that their opinions are given importance in relation to their age and maturity, both in the UN Convention on the Rights of the Child and in the UN Convention on Human Rights (United Nations, 1948, 1989).

In this thesis, as it was of particularly interest to find out the children's own opinions of DTM and autonomy, children's self-reporting was used as one of several data collection measurements. Using Patient-Reported Outcome Measures (PROM) with children and adolescents is a relatively new area, but it has been shown to provide a better understanding of the child's competence and their perspective (Curtin, 2001). The questionnaires used in this thesis were designed to capture children's own experiences of DTM and autonomy and contained statements familiar to children of these ages. To facilitate the children's active participation in the data collection, they had the option to participate in one or two visits, depending on the child's ability to cope. The children participating in studies II, III and IV were aged 9-15, and according to (Matza et al., 2013) it is acceptable to use PROM with these ages, for evaluation and to enable children to express their subjective experiences, feelings and levels of satisfaction.

When planning the individual intervention, a client-centred measurement (COPM) was used. Using the COPM involves children and parents describing 
separately any problems with activities the child wanted to do, or had to do, and then rating the current level of performance and satisfaction with this performance. The child, their parent(s) and the OT then decided on intervention goals reflecting these performance problems. Although using COPM with young children can be a challenge, it worked well with almost all the children. Only two had problems rating both occupational performance and satisfaction, at baseline and at follow-up. Based on the fact that children with ADHD can be impulsive, and can have difficulties paying attention for an extended period of time, it was important that the goals discussed and determined were concise and achievable in a relatively short period of time.

\section{Methodological considerations}

\section{Aspects of generalizability of the findings}

Study I was based on a qualitative approach and the aim was therefore not to generalize the findings, but to investigate a phenomenon experienced in a group of participants (Polit \& Beck, 2016) and to use the findings in further research. Nevertheless, measures were taken to facilitate transferability in the study (Cypress, 2017; Graneheim \& Lundman, 2004). The participants were recruited from a limited geographical area in central Sweden. The purposive sampling gave a broad variety of experiences concerning age, and different forms of housing and activities during the daytime, but an imbalance in gender. All participants had experiences of using a CAD, but the period varied from 1.5 months to two years. Some of the participants were more talkative than others, but they were all willing and able to communicate their experiences, both positive and negative. One limitation is that the findings do not mirror individuals who have problems communicating or individuals using the $\mathrm{CAD}$ for a shorter or longer period of time.

The recruitment of children with ADHD (studies II, III and IV) intended to find children who could benefit from the planned intervention. This means that the present study is not representative of the proportion of difficulties in DTM and TPA for all children with ADHD. One weakness of the intervention studies (studies II and IV) is the relatively small number of participants, and caution should therefore be exercised when generalizing the results. However, the recruitment was from regular child and adolescent psychiatric clinics and a children's habilitation service from different services in Sweden, and the sample may therefore mirror a population of children with ADHD who have time and planning deficits despite medication. A randomization was also carried out (study II) in an effort to avoid systematic bias. Another limitation of study II was the number of drop-outs at follow-up. However, on performing a sensitivity analysis no significant differences were found between the completers and the drop-outs. The relatively small number of participants (studies II and IV) suggests a need 
for further research with larger groups of children with ADHD. Further research is also needed to investigate the long-term effects of time-related interventions.

In study III, the children with ID and the TD children, included in the comparison groups, were samples drawn from a database of children with different diagnoses and TD children. Data from children with ID was gathered by certified OTs working at various children's habilitation services from all parts of Sweden and participating in courses for KaTid certification. The TD children in the database were recruited as a convenience sample from the normal population, self-reported by the parents as being healthy and having no diagnosis, by the OTs participating in the same courses for KaTid certification, and thereafter included in the database. This gives a broad geographical distribution of children in the comparison groups, which increases the possibility of generalizing the findings. Nevertheless, the fact that we do not know the specific level of ID for the children with ID is a limitation. Another limitation in study III is the number of drop-outs of self-ratings of autonomy in children with ID, although a sensitivity analysis did not show any differences in the results.

\section{Choice of design and data collection methods}

In response to the overall aim of this thesis both qualitative and quantitative designs have been used and the data collection methods are in line with this.

Since persons with ID are the target group in Sweden that have had access to compensational interventions including different kind of TADs for the longest time, their experiences of using TADs were of interest in study I. Interviews are often used in occupational therapy (Vessby \& Kjellberg, 2010) and could help health providers to understand the benefits and potential barriers of interventions as well as being a first step in a survey design (Green, 1999). To focus on the specific topic of interest, semi-structured interviews were used (Polit \& Beck, 2016). Depending on the participants' cognitive deficits follow-up questions were also sometimes needed (Arvidsson \& Jonsson, 2006; Kjellberg, 2002) and the participants were prompted to show how they used their CAD. These strategies were useful and improved the interview situation.

The multicentre study design (studies II, III and IV) offered an opportunity to include participants from a variety of different geographical areas, which is considered a strength.

The intervention in studies II and IV lasted for three months. After another three months, with only standard methods of care, a follow-up was carried out. Data collection was performed at baseline and at follow-up, not following the last intervention session. It might have been an advantage to include both a postintervention test and a follow-up, which would have strengthened the study. This was unfortunately not possible due to limited access to the target group. We also aimed to reduce the burden on the families, and the intervention itself had already included a large number of meetings. When investigating the effect of an 
intervention, it is often preferable to have more than two measurement points, and at least three measurement points is suggested (Ployhart \& Vandenberg, 2009). A longer follow-up period with a third data collection point would, on the other hand, have resulted in an even longer waiting period for the control group (study II), which would probably have reduced the number of participants remaining in the study.

The data collection in studies II, III and IV consisted of a structured assessment, parent ratings and self-reports. This gives a broad picture of children's functioning in everyday life. Obtaining information from both children and their parents provides opportunities to see both perspectives and could provide important information concerning the child's health and well-being (Hemmingsson et al., 2017; Klassen, Miller, \& Fine, 2006).

The cross-sectional design of study III made it possible to compare DTM, TPA and autonomy in children with ADHD, children with ID and TD children. The age range of the children was seen as positive since this gave the studies a broader perspective. However, it also resulted in a need to use different versions of the instruments (KaTid, Time-Parent scale and the self-rating of Autonomy) and this complicated the data analysis.

In studies II and IV, the intervention design with children's active participation, may have made positive contribution to the results. Client centeredness, including participation as both an end and a means, is fundamental in occupational therapy (Creek \& Lawson-Porter, 2007; Kielhofner, 2007; Kjellberg et al., 2012). In a review by Wessles et al. (2003), important aspects of assistive devices to be used include whether the user's opinions are considered in the selection of a device, whether the user is motivated, and whether the devices are checked regularly. Children with ADHD can have difficulties planning ahead and sticking to plans (American Psychiatric Association, 2013; Swedish Agency for Health Technology Assessment and Assessment of Social Services, 2013). Despite this, the interventions were implemented with significant results in both TPA and DTM and almost all children completed the intervention period.

\section{Aspects of data analysis and trustworthiness}

A number of strategies were used to increase the trustworthiness of the interviews in study I. To enhance credibility the interview guide was built up rigorously using concrete questions organized in a logical time order to assist the participants with remembering and describing their use of CADs. The information provided was checked continually during the interviews with the participants (Cypress, 2017; Krefting, 1991; Kvale, 1997). To improve confirmability, there were continuous discussions between the two authors concerning plausible interpretations of data, leading to a consensus.

One possible weakness of the multicentre study design in studies II, III and IV is that several people were active in the data collection and intervention 
(studies II and IV), requiring a detailed schedule to coordinate how the assessments and the intervention were carried out. To ensure that the interventions provided were consistent, seminars were held with the OTs involved in the intervention. A risk of deviating from the study design arises if the intervention design is more complex i.e. if interventions are offered by many different people (Horner, Rew, \& Torres, 2006). Intervention fidelity was therefore of particular importance in studies II and IV. This was checked by considering attendance at the education day and the recurring meetings with the OT, the quantity of completed "challenging tasks" and the TADs received by the children. One way to improve the intervention fidelity could have been extended education and supervision of the coaches to ensure compliance with the remediation component. Also, video/audio recordings could have been used to monitor how the coaches supported the children.

Study II could include some degree of bias because the parents, the children and those who performed out the measurements knew which children had received the intervention. In an attempt to reduce this potential bias, the preintervention results were not available at follow-up. Also, the OTs who performed the follow-ups were not involved in the intervention. Parents' ratings could of course also be affected by expectation bias, but all types of measures have both strengths and limitations, and these types of measures are - according to Bikic et al. (2017) - not inferior to observational data and are still of value. In addition, both a structured assessment (the KaTid), and questionnaires (the TimeParent scale and the Time-self-rating) were used.

One strength of study III is that two different methods were used to analyse the data: a group comparison (Polit \& Beck, 2016) and a person-oriented cluster analysis (Bergman et al., 2003). Comparing two or more groups on a specific subject is a useful method for revealing group differences (Polit \& Beck, 2016) . According to Bergman et al. (2003), a cluster analysis gives a thorough description of individual differences and allows for a translation of the results into properties that characterize individuals. This makes it possible to plan and offer individualized interventions based on the individual's difficulties and not only on the diagnosis.

\section{Clinical implications}

The findings in this thesis contribute with new knowledge about DTM, TPA, autonomy and participation in children and adults with ADHD and ID and in young adults with ID, and thus have clinical implications.

Based on the findings, here are some suggestions concerning clinical implications: 
- It is crucial for professionals to enable participation for children, adolescents and young adults with neurodevelopmental disorders during assessment, intervention and evaluation.

- School-age children with ADHD, together with their parents, should be given opportunities to set occupational performance goals and rate their performance and satisfaction based on the COPM. OTs and other professions should therefore consider using concrete goal setting in cooperation with children and their parents to enhance participation and improve the outcome.

- It is important to be observant of DTM and TPA in children and adolescents with ADHD and ID, and to measure TPA and DTM in order to offer tailored interventions.

- A combined intervention of compensation and remediation should be offered to children, adolescents and young adults with neurodevelopmental disorders who have time-related difficulties.

- Psychoeducation focusing on time-related difficulties, consequences in daily activities, and how to enhance participation in activities, should be offered to parents and stakeholders as a stepping stone for further timerelated interventions.

- For children and adolescents with neurodevelopmental disorders and timerelated difficulties there is a need for cooperation between child and adolescent psychiatric clinics, children's habilitation services and schools to achieve improved DTM. Collaboration - and always with the individual participating on his or her own terms - between current healthcare units, housing with special services, day centers and other workplaces for adults, is also important when working with young adults with neurodevelopmental disorders. 


\section{Future research}

An evaluation of this multimodal time-related intervention (studies II and IV) shows the first evidence of efficiency. However, as this is a new intervention directed at children and adolescents with ADHD, there is a need for a number of further studies.

- Due to the relatively small sample size it is important to replicate the research with larger groups of children and adolescents with ADHD.

- A follow-up was performed after 24 weeks. To establish the long-term effects, research will be needed with a longer follow-up period.

- The age range in the present studies intervention study was 9 to 15 years. Research is needed both on children younger than 9 years and on older children than 15 years.

- All children participating in the intervention study were on stable medication for ADHD. Research is needed on children who are not on medication, to investigate the effect of the intervention on non-medicated children.

- Results from the RCT study showed that psychoeducation focusing on time-related issues concerning children with ADHD was appreciated but did not enhance DTM or TPA. However we do not know for certain if whether it was the combination of compensation and remediation that gave the significant results, or whether one of the intervention components offered an advantage. It is recommended that these issues are investigated in a future RCT study.

This thesis showed that children and adolescents with ADHD may have specific deficits in the whole construct of TPA, including time perception, time orientation and time management. The results also showed that diversity in TPA among children and adolescents with ADHD and those with ID did not relate to age.

- These findings need to be investigated further.

Study I in this thesis also showed that participation was sometimes restricted by attitudes towards participation and to the use of TAD.

- There is a need for qualitative and quantitative studies focusing on the use of TAD in activities in daily life and the related hindering and facilitating factors, from the perspectives of children, adolescents and adults with ADHD and those with ID. 


\section{CONCLUSIONS}

A multimodal time-related intervention using compensation including time assistive devices (TADs) and remediation including time skills training increased time processing ability (TPA) and daily time management (DTM) in children with attention-deficit hyperactivity disorder (ADHD) aged 9-15 with time deficits. This is shown in both occupational performance and in satisfaction with the performance. Based on that, it is recommended that TPA and DTM should be measured to identify difficulties in TPA and daily functioning in children with ADHD and to offer time-related interventions in addition to medication. This may give better prerequisites for the daily life of school-age children with ADHD.

The psychoeducation focusing on difficulties in TPA and DTM, which was directed at the parents and coaches of children and adolescents with ADHD, did not increase the children's DTM on its own. However it was appreciated by the participating parents and coaches and led to valuable discussions during the intervention and should therefore be used as a stepping stone for time related interventions.

In the intervention included in this thesis children with ADHD age 9-15 actively participated in goalsetting and often participated in the design of the TAD. This points to the possibility and necessity of enabling children's participation in the intervention process.

This thesis revealed that children with ADHD and intellectual disabilities (ID) have the same overall pattern of TPA but may have a delayed TPA, which affects their DTM and autonomy, and thereby also influences their participation in daily activities. This indicates that they could have specific problems in developing TPA in relation to their age, compared to typically developing (TD) children, and therefore need support in order to develop more advanced levels of TPA. However, not all children with ADHD or ID had specific difficulties with TPA compared to TD children, indicating a need to measure children's TPA in order to tailor a suitable intervention for every child who needs it.

The findings in this thesis deepen and expand our knowledge of time deficits in children and adolescents with ADHD to include difficulties in time orientation, in addition to difficulties with time perception and time management. The findings also show that children and adolescents with ADHD may have a specific difficulty transferring their cognitive functioning in TPA to time-related activities in daily life (DTM).

Experiences from young adults with ID using TADs showed that TADs enabled participation in daily activities and resulted in health benefits, and they 
experienced more of their own control in daily activities using TADs. However, there were participation restrictions related to attitudes from the social network towards participation, and attitudes towards the use of TADs from the individuals themselves and from their social network. Thus, it is of importance that occupational therapists continuously follow-up the use of TADs and their influence on participation in daily life. 


\section{ACKNOWLEDGEMENTS}

I wish to express my deep gratitude to everyone who has contributed to this thesis. No one has been forgotten, but only a few can be mentioned here.

First of all I would like to thank all the participants who took part in my studies. The young adults who generously shared their experiences of using cognitive assistive devices, and all the children, their parents and their coaches for participating in the intervention studies, and for being willing to try a new intervention.

Warm thanks to my three supervisions:

To my supervisor Per A. Gustafsson and to my co-supervisors Anette Kjellberg and Gunnel Janeslätt. You have always being positive, available and encouraging. You have helped me to think by myself when I needed to do so, and have given advice when it was the best thing to do. As a team, you have always contributed to a warm atmosphere and a willingness to share your extensive knowledge. I have enjoyed being supervised by you!

I also want to thank the staff at the child and adolescent psychiatric clinics and the children's habilitation service for their time and support during the data collection process and the occupational therapists who helped to put me in touch with the participants in study I.

Thanks to the occupational therapists who collected data and the ones who performed the interventions with great skill: Lina Backman, Eva Bjuvmar, Asa Björnberg, Marie Donlau, Ann Liljemark, Inger Tollin, Carmen Strömblad and Agneta Östergren.

Research assistant Annika Persson is gratefully acknowledged for her knowledge and accuracy, as well as Elisabet Walinder who helped to compile the comparative data in study III.

Also thanks to Mats Fredrikson for statistical support in study II.

To my co-author Lena Almqvist in study III: Thank you for your valuable statistical support within the cluster analysis.

Thanks to Professor Mats Granlund and Professor Laura Korhonen for their valuable comments on study III.

To Sven Björsten: Thanks for your kindness in allowing me to use your painting "Frukostbild". 
To Kersti Sköld: Thank you for your photos of the time assistive devices.

Thanks to my co-workers and friends at the Habilitation Resource Centre (Habiliteringens resurscenter) in Stockholm, for showing an interest in my research and understanding when I have been away from my clinical work.

My warmest thanks to my manager of many years, Carina Fritzson. I have appreciated your commitment and the confidence you have shown in me while I have been working on this thesis.

I also want to thank all the PhD students and senior researchers at Linköping University's Department of Occupational Therapy and Department of Clinical and Experimental Medicine for interesting seminars with discussions and valuable comments during my years as a PhD student.

Thanks to all my supportive friends.

Special thanks to my PhD colleague and new friend Bharti, for valuable chats about the $\mathrm{PhD}$ process we were both undergoing and about other matters; and to Karin, I always appreciate your interested questions, your great knowledge and your friendship; Elisabet, I am grateful for your friendship and all I learn from you; and Ulla and Ingela, for your friendship over the course of many years matters; and to Ann-Marie, my informal mentor.

To my "Mahjong friends": Eva, Eva, Eva, Lena and Jeanette, your friendship and support are of great value to me; and also to my "Midsummer friends": Anita, Birgitta and Henrik, Göran and Karin. Your interest in my doctoral journey and your help in thinking about things other than research and have helped me cope.

Also thanks to my supportive relatives. To my mother-in law, Mary. My warmest thanks to my sister Berit who has always been by my side. Thank you to my "grown up children" and your partners, and to my step-daughter and partner, for your love and interest: Robert and Malin, Martin and Ida, Annie and Magnus.

And finally, thank you to my beloved husband, Håkan, for always being there, encouraging me and believing in me. For snacks and dinners when I needed them, for letting me talk about my research when I needed to, for technical support and for a genuine interest in my research.

\section{Birgitta Wennberg}

The research was supported by grants from: the Swedish National Association for Disabled Children and Young People (RBU), the Promobilia Foundation, the Sunnerdahls Handikappfond Foundation, the Medical Research Council of Southeast Sweden (FORSS) and the Vårdahl Foundation's idea testing project. Habilitation \& Health, SLSO are also acknowledged for financial support. 


\section{REFERENCES}

Aberg, K. (2012). Manual för Min Tid; verktyg för att undersöka, förstå och hantera tid [Manual for My Time; Tool for examining, under-standing and managing time]. In Swedish.

Abikoff, H., Gallagher, R., Wells, K. C., Murray, D. W., Huang, L., Lu, F., \& Petkova, E. (2013). Remediating organizational functioning in children with ADHD: immediate and long-term effects from a randomized controlled trial. Journal of consulting and clinical psychology, 81(1), 113128. doi: $10.1037 / \mathrm{a} 0029648$

Adolfsson, J. (2012). Kognitiva hjälpmedel. Nationell uppföljning av hjälpmedelsförsörjningen för personer med kognitiva funktionsnedsättningar. [Cognitive tools. National follow-up of the supply of aids for people with cognitive disabilities]. Retrieved from http://www.mynewsdesk.com/material/document/22672/download?resour ce_type=resource_document. In Swedish.

Adolfsson, P., Lindstedt, H., \& Janeslatt, G. (2015). How people with cognitive disabilities experience electronic planning devices. NeuroRehabilitation, 37(3), 379-392. doi:10.3233/nre-151268

Adolfsson, P., Lindstedt, H., Pettersson, I., Hermansson, L. N., \& Janeslatt, G. (2016). Perception of the influence of environmental factors in the use of electronic planning devices in adults with cognitive disabilities. Disability and Rehabilitation: Assistive Technology, 11(6), 493-500. doi:10.3109/17483107.2014.989418

Almqvist, L., \& Granlund, M. (2005). Participation in school environment of children and youth with disabilities: a person-oriented approach.

Scandinavian journal of psychology, 46(3), 305-314. doi:10.1111/j.14679450.2005.00460.x

American Association on Intellectual and Developmental Disabilities. (2010). Intellectual disability : definition, classification, and systems of supports. Washington, DC: American Association on Intellectual and Developmental Disabilities.

American Psychiatric Association. (2013). Diagnostic and statistical manual of mental disorders : (DSM-5) (5 ed.). Arlington, Va.: American Psychiatric Association.

Applegate, S. L., Rice, M. S., Stein, F., \& Maitra, K. K. (2008). Knowledge of results and learning to tell the time in an adult male with an intellectual disability: a single-subject research design. Occupational therapy international, 15(1), 32-44. doi:10.1002/oti.242

Arvidsson, G., \& Jonsson, H. (2006). The impact of time aids on independence and autonomy in adults with developmental disabilities. Occupational therapy international, 13(3), 160-175. 
Barkley, R. A. (1997). Behavioral inhibition, sustained attention, and executive functions: constructing a unifying theory of ADHD. Psychological bulletin, 121(1), 65-94.

Beauchamp, T. L., \& Childress, J. F. (2013). Principles of biomedical ethics. New York: Oxford University Press.

Bergman \& El-Khouri. (2002). SLEIPNER: A statistical package for patternoriented anayses (Version 2.1)[Computer software]. Department of Psychology. Stockholm University. Stockholm.

Bergman, L. R., Magnusson, D., \& El-Khouri, B. M. (2003). Studying individual development in an interindividual context: A person-oriented approach. Mahwah: NJ: Erlbaum Associates, Inc.

Bikic, A., Reichow, B., McCauley, S. A., Ibrahim, K., \& Sukhodolsky, D. G. (2017). Meta-analysis of organizational skills interventions for children and adolescents with Attention-Deficit/Hyperactivity Disorder. Clinical Psychological Review, 52, 108-123. doi:10.1016/j.cpr.2016.12.004

Björck-Åkesson, E., \& Granlund, M. . (2004). Delaktighet - ett centralt begrepp i WHO:s klassifikation av funktionstillstånd, funktionshinder och hälsa (ICF). In A. Gustavsson (Ed.), Delaktighetens språk (pp. 29-48). Lund: Studentlitteratur. In Swedish.

Bolte, S., Mahdi, S., Coghill, D., Gau, S. S., Granlund, M., Holtmann, M., . . . Selb, M. (2018). Standardised assessment of functioning in ADHD: consensus on the ICF Core Sets for ADHD. European child \& adolescent psychiatry, 27(10), 1261-1281. doi:10.1007/s00787-018-1119-y

Breaux, R. P., Langberg, J. M., Bourchtein, E., Eadeh, H. M., Molitor, S. J., \& Smith, Z. R. (2019). Brief homework intervention for adolescents with ADHD: Trajectories and predictors of response. School Psychology, 34(2), 201-211. doi:10.1037/spq0000287.

Breaux, R. P., Langberg, J. M., Molitor, S. J., Dvorsky, M. R., Bourchtein, E., Smith, Z. R., \& Green, C. D. (2019). Predictors and Trajectories of Response to the Homework, Organization, and Planning Skills (HOPS) Intervention for Adolescents With ADHD. Behavior therapy, 50(1), 140154. doi:10.1016/j.beth.2018.04.001.

Bylholt, C. (1997). A Review of the Literature on the Acquisition and Development of Time Concepts in Children. CAEDHH Journal/La Revue ACESM, 23(2-3), 119-124.

Cardol, M., De Jong, B. A., \& Ward, C. D. (2002). On autonomy and participation in rehabilitation. Disability and Rehabilitation: An International, Multidisciplinary Journal, 24(18), 970-974; discussion 9751004.

Chan, R. C. K. (2002). Active participation and autonomy: An ultimate target for rehabilitation. Disability and Rehabilitation: An International, Multidisciplinary Journal, 24(18), 983-984. doi:10.1080/09638280210152030.

Charters, E., Gillett, L., \& Simpson, G. K. (2015). Efficacy of electronic portable assistive devices for people with acquired brain injury: a systematic 
review. Neuropsychological rehabilitation, 25(1), 82-121.

doi:10.1080/09602011.2014.942672.

Cieza, A., Geyh, S., Chatterji, S., Kostanjsek, N., Ustun, B., \& Stucki, G. (2005).

ICF linking rules: an update based on lessons learned. Journal of

rehabilitation medicine, 37(4), 212-218.

doi:10.1080/16501970510040263.

Cohen, J. (1988). Statistical power analysis for the behavioral sciences.

Hillsdale: L. Erlbaum Associates.

Creek, J., \& Lawson-Porter, A. (2007). Contemporary issues in occupational therapy : reasoning and reflection. Chichester: Wiley.

Cup, E. H., Scholte op Reimer, W. J., Thijssen, M. C., \& van Kuyk-Minis, M. A. (2003). Reliability and validity of the Canadian Occupational Performance Measure in stroke patients. Clinical rehabilitation, 17(4), 402-409. doi:10.1191/0269215503cr635oa.

Curtin. (2001). Eliciting Children's Voices in Qualitative Research. The American Journal of Occupational Therapy, Maj/June(55(3).

Cypress, B. S. (2017). Rigor or Reliability and Validity in Qualitative Research: Perspectives, Strategies, Reconceptualization, and Recommendations.

Dimension of Critical Care Nursing, 36(4), 253-263. doi:10.1097/dcc.0000000000000253.

Danielsson, H., Henry, L., Ronnberg, J., \& Nilsson, L. G. (2010). Executive functions in individuals with intellectual disability. Research in Developing Disabilities, 31(6), 1299-1304. doi:10.1016/j.ridd.2010.07.012

Davies, D. K., Stock, S. E., \& Wehmeyer, M. L. (2002). Enhancing independent time-management skills of individuals with mental retardation using a Palmtop personal computer. Mental retardation, 40(5), 358-365. doi:10.1352/0047-6765(2002)040<0358:eitmso>2.0.co;2.

Diamond, A. (2013). Executive functions. Annual review of psychology, 64, 135168. doi:10.1146/annurev-psych-113011-143750.

Dipipi-hoy, C., Jitendra, A. K., \& Kern, L. (2009). Effects of Time Management Instruction on adults.pdf>. The Journal of Special Education, 43(3), 145149.

Eiser, C., \& Varni, J. W. (2013). Health-related quality of life and symptom reporting: similarities and differences between children and their parents. European journal of pediatrics, 172(10), 1299-1304. doi:10.1007/s00431013-2049-9.

Eriksson, L., \& Granlund, M. (2004). Perceived participation. A comparison of students with disabilities and students without disabilities. Scandinavian Journal of Disability Research, 6(3), 206-224. doi:10.1080/15017410409512653.

Eriksson, L., Welander, J., \& Granlund, M. (2007). Participation in Everyday School Activities For Children With and Without Disabilities. Journal of Developmental and Physical Disabilities, 19(5), 485-502. doi:10.1007/s10882-007-9065-5.

Evans, S. W., Langberg, J. M., Egan, T., \& Molitor, S. J. (2014). Middle schoolbased and high school-based interventions for adolescents with ADHD. 
Child and adolescent psychiatric clinics of North America, 23(4), 699715. doi:10.1016/j.chc.2014.05.004.

Evans, S. W., Owens, J. S., \& Bunford, N. (2014). Evidence-based psychosocial treatments for children and adolescents with attention-deficit/hyperactivity disorder. Journal of Clinical Child \& Adolescent Psychology, 43(4), 527551. doi:10.1080/15374416.2013.850700.

Faraone, S. V., Asherson, P., Banaschewski, T., Biederman, J., Buitelaar, J. K., Ramos-Quiroga, J. A., . . . Franke, B. (2015). Attentiondeficit/hyperactivity disorder. Nature Reviews Disease Primers, 1, 15020. doi:10.1038/nrdp.2015.20.

Faraone, S. V., Biederman, J., \& Mick, E. (2006). The age-dependent decline of attention deficit hyperactivity disorder: a meta-analysis of follow-up studies. Psychological medicine, 36(2), 159-165. doi:10.1017/s003329170500471x.

Ferrin, M., Perez-Ayala, V., El-Abd, S., Lax-Pericall, T., Jacobs, B., Bilbow, A., \& Taylor, E. (2016). A Randomized Controlled Trial Evaluating the Efficacy of a Psychoeducation Program for Families of Children and Adolescents With ADHD in the United Kingdom: Results After a 6Month Follow-Up. Journal of attention disorders. doi:10.1177/1087054715626509.

Forer, R. K., \& Keogh, B. K. (1971). Time understanding of learning disabled boys. Exceptional children, 37(10), 741-743.

Gaub, M., \& Carlson, C. L. (1997). Gender differences in ADHD: a metaanalysis and critical review. Journal of the American Academy of Child \& Adolescent Psychiatry, 36(8), 1036-1045. doi:10.1097/00004583199708000-00011.

Gillespie, A., Best, C., \& O'Neill, B. (2012). Cognitive function and assistive technology for cognition: a systematic review. Journal of the International Neuropsychological Society, 18(1), 1-19. doi:10.1017/s1355617711001548.

Gillette, Y., \& DePompei, R. (2004). The potential of electronic organizers as a tool in the cognitive rehabilitation of young people. NeuroRehabilitation, 19(3), 233-243.

Giori, A. (1985). Setch of a psychological phenomenological method. In A. Giori (Ed.), Phenomenology and Psychological Reearch (pp. 8-22). Pittsburg: Duqusne University Press.

Graneheim, U. H., \& Lundman, B. (2004). Qualitative content analysis in nursing research: concepts, procedures and measures to achieve trustworthiness. Nurse Education Today, 24(2), 105-112. doi:10.1016/j.nedt.2003.10.001.

Granlund, M. (2013). Participation-challenges in conceptualization, measurement and intervention. Child Care Health Development, 39(4), 470-473. doi:10.1111/cch.12080.

Granlund, M., Bond, A., Lindström, E., \& Wennberg, B. (1995). Assistive Technology and Persons with Developmental Disabilities. Technology and Disability, 4(3-4), 205-214. doi:10.3233/TAD-1995-43-404. 
Green, J. (1999). Qualitative methods. The Epidemiology in Practice.

Gureasko-Moore, S., Dupaul, G. J., \& White, G. P. (2006). The effects of selfmanagement in general education classrooms on the organizational skills of adolescents with ADHD. Behavior modification, 30(2), 159-183. doi:10.1177/0145445503259387.

Hemmingsson, H., Olafsdottir, L. B., \& Egilson, S. T. (2017). Agreements and disagreements between children and their parents in health-related assessments. Disability and Rehabilitation: An International, Multidisciplinary Journal, 1-14. doi:10.1080/09638288.2016.1189603.

Horner, S., Rew, L., \& Torres, R. (2006). Enhancing intervention fidelity: a means of strengthening study impact. Journal of Specialists in Pediatric Nursing, 11(2), 80-89. doi:10.1111/j.1744-6155.2006.00050.x.

Imms, C., Adair, B., Keen, D., Ullenhag, A., Rosenbaum, P., \& Granlund, M. (2016). 'Participation': a systematic review of language, definitions, and constructs used in intervention research with children with disabilities. Developmental Medicine \& Child Neurology, 58(1), 29-38. doi:10.1111/dmen.12932.

Imms, C., Granlund, M., Wilson, P. H., Steenbergen, B., Rosenbaum, P. L., \& Gordon, A. M. (2016). Participation, both a means and an end: a conceptual analysis of processes and outcomes in childhood disability. Developmental medicine and child neurology. doi:10.1111/dmcn.13237

Intellectual, A. A. o., \& and Developmental Disabilities (AAIDD). (2010). Intellectual Disability: Definition, Classification, and Systems of Supports (11th Edition). Washington.

ISO 21802:2019, Assistive products, Guidelines on cognitive accessibility, Daily time management, (2019).

Jacobsson, H. (1999). Hjälpmedlets möjligheter att kompensera nedsatt begåvning/cognition [The assisive devices oppertunities to compensate for impaired intellect/cognition]. Landstinget Dalarna. Falun. In Swedish.

Janeslätt, G. (2009). Time for time. Assessment of time processing ability and daily time management in children with and without disabilities. (Doctoral thesis), Karolinska Institutet, Stockholm, Sweden.

Janeslätt, G. (2012). Validity in assessing time processing ability, test equating of KaTid-Child and KaTid-Youth. Child: care, health and development, 38(3), 371-378. doi:10.1111/j.1365-2214.2011.01249.x.

Janeslätt, G., Granlund, M., Alderman, I., \& Kottorp, A. (2008). Development of a new assessment of time processing ability in children, using Rasch analysis. Child Care Health Development, 34(6), 771-780. doi:10.1111/j.1365-2214.2008.00865.x.

Janeslätt, G., Granlund, M., \& Kottorp, A. (2009). Measurement of time processing ability and daily time management in children with disabilities. Disability and Health Journal, 2, 15-19.

Janeslätt, G., Granlund, M., Kottorp, A., \& Almqvist, L. (2010). Patterns of Time Processing Ability in Children with and without Developmental Disabilities. Journal of Applied Research in Intellectual Disabilities, 23(3), 250-262. doi:10.1111/j.1468-3148.2009.00528.x. 
Janeslätt, G., Kottorp, A., \& Granlund, M. (2014). Evaluating intervention using time aids in children with disabilities. Scandinavian journal of occupational therapy, 21(3), 181-190. doi:10.3109/11038128.2013.870225.

Janeslätt, G., Lindstedt, H., \& Adolfsson, P. (2014). Daily time management and influence of environmental factors on use of electronic planning devices in adults with mental disability. Disabil Rehabil Assist Technol. doi:10.3109/17483107.2014.917124.

Janeslätt, G., Wallin Ahlström, S., \& Granlund, M. (2019). Intervention in timeprocessing ability, daily time management and autonomy in children with intellectual disabilities aged 10-17 years - A cluster randomised trial. Australian Occupatinal Therapy Journal. doi:10.1111/1440-1630.12547.

Kielhofner, G. (2007). Model of human occupation : theory and application (4. ed. ed.). Baltimore MD: Lippincott Williams \& Wilkins.

Kjellberg, A. (2002). More or less independent. Disability and rehabilitation, 24(16), 828-840. doi:10.1080/09638280210131745.

Kjellberg, A., Kahlin, I., Haglund, L., \& Taylor, R. R. (2012). The myth of participation in occupational therapy: reconceptualizing a client-centred approach. Scandinavian Journal of Occupation Therapy, 19(5), 421-427. doi:10.3109/11038128.2011.627378.

Klassen, A. F., Miller, A., \& Fine, S. (2006). Agreement between parent and child report of quality of life in children with attentiondeficit/hyperactivity disorder. Child: Care Health and Development, 32(4), 397-406. doi:10.1111/j.1365-2214.2006.00609.x.

Kofler, M. J., Sarver, D. E., Harmon, S. L., Moltisanti, A., Aduen, P. A., Soto, E. F., \& Ferretti, N. (2018). Working memory and organizational skills problems in ADHD. Journal of Child Psychology and Psychiatry, 59(1), 57-67. doi:10.1111/jcpp.12773.

Koyama, T., \& Wang, H. T. (2011). Use of activity schedule to promote independent performance of individuals with autism and other intellectual disabilities: a review. Reserach in Developmental Disabilities 32(6), 2235 2242. doi:10.1016/j.ridd.2011.05.003.

Krefting, L. (1991). Rigor in qualitative research: the assessment of trustworthiness. Amercan Journal of Occupational Therapy 45(3), 214222. doi:10.5014/ajot.45.3.214.

Kvale, S. (1997). Den kvalitativa forskningsintervjun [The qualitative research interview]. Lund: Studentlitteratur. In Swedish.

Kylén, G. (1986). Begåvning och begåvningshandikapp. [ The intellect and intellectual handicaps]. Bromma, Stockholm: Stiftelsen ALA. In Swedish.

Lachapelle, Y., Wehmeyer, M. L., Haelewyck, M. C., Courbois, Y., Keith, K. D., Schalock, R., .. . Walsh, P. N. (2005). The relationship between quality of life and self-determination: an international study. Journal of Intellectual Disability Research 49(Pt 10), 740-744. doi:10.1111/j.13652788.2005.00743.x. 
Langberg J, E. N., Girio-Herrera E., Becker S:, Vaughn A., Altaye M. (2011). Materials Organization, Plnning, and Homework Completion in MiddleSchool Students with ADHD: Impact on Adademic Performance. School mental health, 3, 93-101.

Langberg, J. M., Becker, S. P., Epstein, J. N., Vaughn, A. J., \& Girio-Herrera, E. (2013). Predictors of Response and Mechanisms of Change in an Organizational Skills Intervention for Students with ADHD. Journal of child and family studies, 22(6). doi:10.1007/s10826-012-9662-5.

Langberg, J. M., Epstein, J. N., Becker, S. P., Girio-Herrera, E., \& Vaughn, A. J. (2012). Evaluation of the Homework, Organization, and Planning Skills (HOPS) Intervention for Middle School Students with ADHD as Implemented by School Mental Health Providers. School psychology review, 41(3), 342-364.

Langberg, J. M., Epstein, J. N., \& Graham, A. J. (2008). Organizational-skills interventions in the treatment of ADHD. Expert review of neurotherapeutics, 8(10), 1549-1561. doi:10.1586/14737175.8.10.1549.

Langberg, J. M., Epstein, J. N., Urbanowicz, C. M., Simon, J. O., \& Graham, A. J. (2008). Efficacy of an organization skills intervention to improve the academic functioning of students with attention-deficit/hyperactivity disorder. School Psychology Quarterly, 23(3), 407-417. doi:10.1037/1045-3830.23.3.407.

Law, M., Baptiste, S., Carswell, A., McColl, M. A., Polatajko, H. J., \& Pollock, N. (2005). Canadian Occupational Performance Measure (4th ed.). Ottawa, ON: CAOT Publications ACE.

Leopold, A., Lourie, A., Petras, H., \& Elias, E. (2015). The use of assistive technology for cognition to support the performance of daily activities for individuals with cognitive disabilities due to traumatic brain injury: The current state of the research. NeuroRehabilitation, 37(3), 359-378. doi:10.3233/nre-151267.

Lequia, J., Machalicek, W., \& Rispoli, M. J. (2012). Effects of activity schedules on challenging behavior exhibited in children with autism spectrum disorders: A systematic review. Research in Autism Spectrum Disorders, 6(1), 480-492. doi:10.1016/j.rasd.2011.07.008.

Levén, A. (2007). Postponed Plans : Prospective Memory and Intellectual Disability. (409 Doctoral thesis, comprehensive summary), Institutionen för beteendevetenskap och lärande. Retrieved from http://urn.kb.se/resolve?urn=urn:nbn:se:liu:diva-10382 DiVA database.

Levén, A., Lyxell, B., Andersson, J., Danielsson, H., \& Rönnberg, J. (2008). Prospective Memory, Working Memory, Retrospective Memory and SelfRated Memory Performance in Persons with Intellectual Disability. Scandinavian Journal of Disability Research, 10(3), 147-165. doi:10.1080/15017410802144444.

Lindblad, I., Svensson, L., Landgren, M., Nasic, S., Tideman, E., Gillberg, C., \& Fernell, E. (2013). Mild intellectual disability and ADHD; a comparative study of school age children's adaptive abilities. Acta Paediatrica, 102(10), 1027-1031. doi:10.1111/apa.12351. 
Lindstedt, H., \& Umb-Carlsson, O. (2013). Cognitive assistive technology and professional support in everyday life for adults with ADHD. Disability and Rehabilitation: Assistive Technology, 8(5), 402-408. doi:10.3109/17483107.2013.769120.

Malterud, K. (1993). Shared Understanding of the Qualitative Research Process. Guidelines for the Medical Researcher. Family practice, 10(2), 201-206.

Malterud, K., \& Midenstrand, M. (2009). Kvalitativa metoder i medicinsk forskning : en introduktion [Qualitative methods in Medical Research: an Introduction]. Lund: Studentlitteratur. In Swedish.

Matza, L. S., Patrick, D. L., Riley, A. W., Alexander, J. J., Rajmil, L., Pleil, A. M., \& Bullinger, M. (2013). Pediatric patient-reported outcome instruments for research to support medical product labeling: report of the ISPOR PRO good research practices for the assessment of children and adolescents task force. Value in Health, 16(4), 461-479. doi:10.1016/j.jval.2013.04.004.

Maulik, P. K., Mascarenhas, M. N., Mathers, C. D., Dua, T., \& Saxena, S. (2011). Prevalence of intellectual disability: a meta-analysis of population-based studies. Research in Developmental Disabilities, 32(2), 419-436. doi:10.1016/j.ridd.2010.12.018.

Maxwell, G. (2012). Bringing more to particiaption. (Doctoral thesis), University Jönköping, Sweden. (16).

McColl, M. A. (2003). The theoretical basis of occupational therapy. Thorofare, NJ: SLACK Inc.

McColl, M. A., Law, M. C., \& Stewart, D. (2015). Theoretical basis of occupational therapy. Thorofare, N.J.: SLACK.

McColl, M. A., Paterson, M., Davies, D., Doubt, L., \& Law, M. (2000). Validity and community utility of the Canadian Occupational Performance Measure. Canadian Journal of Occupational Therapy, 67(1), 22-30. doi:10.1177/000841740006700105.

Mechling, L. C. (2011). Review of twenty-first century portable electronic devices for persons with moderate intellectual disabilities and autism spectrum disorders. Education and Training in Autism and Developmental Disabilities, 46(4), 479-498.

Mioni, G., Santon, S., Stablum, F., \& Cornoldi, C. (2016). Time-based prospective memory difficulties in children with ADHD and the role of time perception and working memory. Child Neuropsychology, 1-21. doi:10.1080/09297049.2016.1172561.

National Board of Health and Welfare. (2014). Stöd till barn, ungdomar och vuxna med ADHD : ett kunskapsstöd, [Support for children, adolescents and adults with adhd - a knowledge support]. Retrieved from http://www.socialstyrelsen.se/publikationer2014/2014-10-42. In Swedish.

National Board of Health and Welfare. (2015). Bedöma barns mognad för delaktighet. Kunskapsstöd för socialtjänsten, hälso- och sjukvården samt tandvården. [Assess children's maturity for participation. Knowledge support for social services, health care and dental care]. In Swedish. 
National Institute for Heath and Care Excellence. (2009, feb 2016). Attention deficit hyperactivity disorder: diagnosis and management. Retrieved from

http://www.rcpsych.ac.uk/usefulresources/publications/niceguidelines/978 1854334718.aspx.

Noreika, V., Falter, C. M., \& Rubia, K. (2013). Timing deficits in attentiondeficit/hyperactivity disorder (ADHD): evidence from neurocognitive and neuroimaging studies. Neuropsychologia, 51(2), 235-266. doi:10.1016/j.neuropsychologia.2012.09.036.

Owen, A. L., \& Wilson, R. R. (2006). Unlocking the riddle of time in learning disability. Journal of intellectual disabilities, 10(1), 9-17. doi:10.1177/1744629506062269.

Peny-Dahlstrand, M., Krumlinde-Sundholm, L., \& Gosman-Hedstrom, G. (2012). Is autonomy related to the quality of performance of everyday activities in children with spina bifida? Disability and rehabilitation, 34(6), 514-521. doi:10.3109/09638288.2011.610495.

Persson, M., Janeslatt, G., \& Peny-Dahlstrand, M. (2017). Daily time management in children with spina bifida. Journal of pediatric rehabilitation medicine, 10(3-4), 295-302. doi:10.3233/prm-170459

Ployhart, R. E., \& Vandenberg, R. J. (2009). Longitudinal Research: The Theory, Design, and Analysis of Change. Journal of Management, 36(1), 94-120. doi:10.1177/0149206309352110.

Polanczyk, G. V., Salum, G. A., Sugaya, L. S., Caye, A., \& Rohde, L. A. (2015). Annual research review: A meta-analysis of the worldwide prevalence of mental disorders in children and adolescents. Journal of Child Psychology and Psychiatry, 56(3), 345-365. doi:10.1111/jcpp.12381.

Polatajko, H. J., Townsend, E.A. \& Craik, J.,. ( 2007). Canadian Model of Occupational Performance and Engagement (CMOP-E). In E. Townsend \& H.J. Polatajko (Ed.), Enabling Occupation II: Advancing an Occupational Therapy Vision of Health, Well-being, \& Justice through Occupation. (pp. 22-36.). Ottawa: ON: CAOT Publications ACE. .

Polit, D. F., \& Beck, C. T. (2016). Nursing research: generating and assessing evidence for nursing practice. Philadelphia: Wolters Kluwer.

Rosenberg, L. (2015). The Associations Between Executive Functions' Capacities, Performance Process Skills, and Dimensions of Participation in Activities of Daily Life Among Children of Elementary School Age. Applied Neuropsychology: Child, 4(3), 148-156. doi:10.1080/21622965.2013.821652.

Rubia, K., Halari, R., Christakou, A., \& Taylor, E. (2009). Impulsiveness as a timing disturbance: neurocognitive abnormalities in attention-deficit hyperactivity disorder during temporal processes and normalization with methylphenidate. Philosophical Transactions of the Royal Society Biological Sciences, 364(1525), 1919-1931. doi:10.1098/rstb.2009.0014

Shaw, P., Malek, M., Watson, B., Sharp, W., Evans, A., \& Greenstein, D. (2012). Development of cortical surface area and gyrification in attention- 
deficit/hyperactivity disorder. Biological psychiatry, 72(3), 191-197. doi:10.1016/j.biopsych.2012.01.031.

Sigafoos, A. D., Feinstein, C. B., Damond, M., \& Reiss, D. (1988). The measurement of behavioral autonomy in adolescence: the autonomous functioning checklist. Adolescent psychiatry, 15, 432-462.

Sköld, A., \& Janeslätt, G. K. (2017). Self-rating of daily time management in children: psychometric properties of the Time-S. Scandinavian journal of occupational therapy, 24(3), 178-186. doi:10.1080/11038128.2016.1185465.

Smith, A., Taylor, E., Rogers, J. W., Newman, S., \& Rubia, K. (2002). Evidence for a pure time perception deficit in children with ADHD. Journal of Child Psychology and Psychiatry, 43(4), 529-542.

Stevenson, R. E., Procopio-Allen, A. M., Schroer, R. J., \& Collins, J. S. (2003). Genetic syndromes among individuals with mental retardation. American Journal of Medical Genetetics 123a(1), 29-32. doi:10.1002/ajmg.a.20492.

Swedish Agency for Health Technology Assessment and Assessment of Social Services. (2013). ADHD : diagnostik och behandling, vårdens organisation och patientens delaktighet : en systematisk litteraturöversikt [ADHD - diagnostics and treatment, organization of the health care and patient involvement: A systematic literature review]. Retrieved from http://www.sbu.se/217. In Swedish.

Söderstrom, S., Ostby, M., Bakken, H., \& Ellingsen, K. E. (2019). How using assistive technology for cognitive impairments improves the participation and self-determination of young adults with intellectual developmental disabilities. Journal of intellectual disabilities, 1744629519882582. doi:10.1177/1744629519882582.

Thomas, R., Sanders, S., Doust, J., Beller, E., \& Glasziou, P. (2015). Prevalence of attention-deficit/hyperactivity disorder: a systematic review and metaanalysis. Pediatrics, 135(4), e994-1001. doi:10.1542/peds.2014-3482.

Toplak, M. E., Dockstader, C., \& Tannock, R. (2006). Temporal information processing in ADHD: findings to date and new methods. Journal of neuroscience methods, 151(1), 15-29. doi:10.1016/j.jneumeth.2005.09.018.

Townsend, E. A., \& Polatajko, H. J. (2013). Enabling occupation II : advancing an occupational therapy vision for health, well-being \& justice through occupation : 9th Canadian occupational therapy guidelines. Ottawa, Ontario: Canadian Association of Occupational Therapists.

United Nations. (1948). Universal declaration of human rights. Retrieved from https://www.refworld.org/docid/3ae6b3712c.html [accessed 2 November 2019]

United Nations. (1989, sept 1990). Convention on the rights of the child, . Retrieved from http://www.ohchr.org/EN/ProfessionalInterest/Pages/CRC.aspx

Wahlstedt, C. (2009). Neuropsychological deficits in relation to symptoms of ADHD: independent contributions and interactions. Child Neuropsychology, 15(3), 262-279. doi:10.1080/09297040802524198 
Wahlstedt, C., Thorell, L. B., \& Bohlin, G. (2009). Heterogeneity in ADHD: neuropsychological pathways, comorbidity and symptom domains. Journal of abnormal child psychology, 37(4), 551-564. doi:10.1007/s10802-008-9286-9.

Wehmeyer, M., \& Kelchner, K. (1995). The Arc's self-determination scale. Arlington, TX:The Arc National Headquarters.

Wehmeyer, M. L., Palmer, S. B., Smith, S. J., Davies, D. K., \& Stock, S. (2008). The Efficacy of Technology Use by People with Intellectual Disability: A Single-Subject Design Meta-Analysis. Journal of Special Education Technology, 23(3), 21-30. doi:10.1177/016264340802300303.

Wennberg B., Sjödin. L., Buchholz M. \& Janeslätt G. (2016). Kognitivt stöd i vardagen. [Cognitive support in every day activites]. In A.-C. Eliasson, H. Lidström, \& M. Peny-Dahlstrand (Eds.), Arbetsterapi för barn och ungdom [Occupational therapy for children and adolescents] (pp. 267280). Lund: Studentlitteratur. In Swedish.

Vessby, K., \& Kjellberg, A. (2010). Participation in Occupational Therapy Research: A Literature Review. British Journal of Occupational Therapy, 73(7), 319-326. doi:10.4276/030802210X12759925544380.

Wessels, R., Dijcks, B., Soede, M., Gelderblom, G. J., \& De Witte, L. (2003). Non-use of provided assistive technology devices, a literature overview. Technology \& Disability, 15(4), 231-238.

Willcutt, E. G. (2012). The prevalence of DSM-IV attention-deficit/hyperactivity disorder: a meta-analytic review. Neurotherapeutics : the journal of the American Society for Experimental NeuroTherapeutics, 9(3), 490-499. doi:10.1007/s13311-012-0135-8.

Willfors, C., Poltrago, L., Berggren, S., Coco, C., Anckarsäter, H., Lichtenstein, P., . . Bölte, S. (2014). On the role of non-shared environment for executive functioning in ADHD: a twin-differences design study. International Journal of Developmental Disabilities, 60(3), 163-173. doi:10.1179/2047387714Y.0000000041.

World Health Organization. (2007). International classification of functioning, disability and health [Elektronisk resurs] children and youth version : ICF-CY Retrieved from http://apps.who.int/iris/handle/10665/43737

World Medical Association of Helsinki. (2008). World Medical Association declaration of Helsinki : ethical principles for medical research involving human subjects. Seoul Guildford: Canary Publications.

Wressle, E., Eeg-Olofsson, A. M., Marcusson, J., \& Henriksson, C. (2002). Improved client participation in the rehabilitation process using a clientcentred goal formulation structure. Journal of rehabilitation medicine, 34(1), 5-11.

Wright, D. B., London, K., \& Field, A. P. (2011). Using Bootstrap Estimation and the Plug-in Principle for Clinical Psychology Data. Journal of Experimental Psychopathology, 2(2), 252-270. doi:10.5127/jep.013611. 


\section{Papers}

The papers associated with this thesis have been removed for copyright reasons. For more details about these see:

http://urn.kb.se/resolve?urn=urn:nbn:se:liu:diva-162113 


\title{
FACULTY OF MEDICINE AND HEALTH SCIENCES
}

\author{
Linköping University Medical Dissertation No. 1717, 2019 \\ Center for Social and Affective Neuroscience (CSAN) \\ Department of Clinical and Experimental Medicine (IKE) \\ Linköping University \\ SE-581 83 Linköping, Sweden
}

www.liu.se 